\title{
Material Risks of Homeopathic Medicinal Products: Regulatory Frameworks, Results of Preclinical Toxicology, and Clinical Meta-Analyses and Their Implications
}

\author{
Michael Habs ${ }^{a} \quad$ Michael Koller ${ }^{b}$ \\ ${ }^{a}$ Faculty of Medicine, LMU - University of Munich, Munich, Germany; ${ }^{b}$ Center for Clinical Studies, University Hospital \\ Regensburg, Regensburg, Germany
}

\section{Keywords}

Homeopathic medicinal products · Toxicological assessment $\cdot$ Safety $\cdot$ Material risks $\cdot$ Balanced risk assessment $\cdot$ Decision making

\begin{abstract}
Homeopathy is widely used and broadly accepted by health care professionals and the general public but less in academic circles. To assess possible material health risks of homeopathic medicinal products, it is necessary to identify, select, and synthesize the findings of recent reviews of controlled homeopathic clinical trials. Matching these findings with experimental data from toxicological studies helps to clarify what is known and not known about the material risks of homeopathic medicines. Rules for toxicological risk assessment and management need to be applied independently of individual attitudes towards specific therapeutic options. European regulatory bodies have developed special protocols and decision trees to assure the safety of nonindividualized homeopathic remedies. This narrative review leads to suggestions that could ease and improve toxicological decision making. No homeopathy-specific type or pattern of side effects could be extracted from the meta-analysis data. No differences in the frequency of adverse reactions between homeopathic treatment and placebo treatment could be seen, no matter whether adverse events were reported in a quantitative or a qualitative manner. Some patterns of side effects show that adverse reactions do not necessarily correlate with treatment but with the condition of the patient.
\end{abstract}

Overall, the controlled clinical data available for the material risk assessment of homeopathic remedies support the statement that, if a risk exists, it must be so small that it has not yet been established. To make our risk findings useful for personal decisions regarding homeopathy, we provide a thought experiment based on four different health situations and ask the question: is homeopathy as a monotherapy or as an add-on treatment an option or should it be rejected?

(c) 2020 The Author(s)

Published by S. Karger AG, Basel

\section{Schlüsselwörter \\ Homöopathika · Toxikologische Bewertung . \\ Sicherheit · Substanzbedingte Risiken · Ausgewogene \\ Risikobewertung · Entscheidungskriterien}

\section{Zusammenfassung}

Die Homöopathie ist weit verbreitet und sowohl bei den Gesundheitsberufen als auch der Bevölkerung breit akzeptiert, während sie in akademischen Kreisen auf Skepsis stößt. Um mögliche substanzbedingte Risiken von Homöopathika zu beurteilen, wurden die Ergebnisse neuerer Übersichtsarbeiten zu kontrollierten klinischen Studien identifiziert, die Berichte zu Nebenwirkungen selektiert und ihre Befunde bewertet. Der Abgleich dieser klinischen Befunde mit den experimentellen Daten aus entsprechenden toxikologischen Studien hilft abzuklären, was zum substanzbedingten Risiko homöopathi-

\section{karger@karger.com} www.karger.com $/ \mathrm{cmr}$

Karger $\frac{1}{*}$

BOPEN ACCESS
(C) 2020 The Author(s)

Published by S. Karger AG, Basel

This is an Open Access article licensed under the Creative Commons Attribution-NonCommercial-4.0 International License (CC BY-NC) (http://www.karger.com/Services/OpenAccessLicense), applicable to the online version of the article only. Usage and distribution for commercial purposes requires written permission. 
scher Arzneimittel tatsächlich bekannt ist oder nicht. Die Regeln des toxikologischen Assessments haben unabhängig davon zu erfolgen, ob eine Therapieoption der persönlichen Einstellung mehr oder weniger entspricht. Die europäischen Aufsichtsbehörden haben spezielle Vorgehensweisen und Entscheidungsraster zur Sicherheitsbewertung homöopathischer Fertigarzneimittel entwickelt. Die Herangehensweise dieser Übersichtsarbeit führt zu Empfehlungen, die helfen, toxikologische Entscheidungsfindungen zu vereinheitlichen und damit zu verbessern. Aus den Nebenwirkungsberichten der MetaAnalysen lässt sich kein Muster ableiten, das spezifisch für Homöopathika wäre. Unterschiede in der Häufigkeit von unerwünschten Ereignissen zwischen Homöopathika und Placebo ließen sich nicht zeigen, unabhängig davon, ob die Nebenwirkungen qualitativ oder quantitativ berichtet wurden. In einigen Fällen korrelierten die berichteten Nebenwirkungsmuster eher mit den Beschwerdebildern der Patienten als mit der Behandlung. Insgesamt unterstützen die Ergebnisse der verfügbaren kontrollierten klinischen Studien die Aussage, dass ein substanzspezifisches Risiko homöopathischer Fertigarzneien nicht existiert oder so gering ist, dass es bisher nicht belegt ist. Um unsere Erkenntnisse zu Risiken der Homöopathie für persönliche Entscheidungsfindungen nutzen zu können, haben wir ein Gedankenexperiment entwickelt. In vier unterschiedlichen Gesundheitssituationen stellen wir die Frage: Ist Homöopathie als Monotherapie oder als Zusatztherapie eine Behandlungsoption oder sollte sie abgelehnt werden?

(c) 2020 S. Karger AG, Basel

\section{Introduction}

Samuel Hahnemann (1755-1843) was the founder of homeopathy. The utilization of homeopathic medicinal products is popular and continuingly increasing, being a worldwide available form of complementary and alternative medicines and a medical system with a long-standing tradition of about 200 years [1]. For decades, the basis and evidence of the clinical efficacy of homeopathy have been controversial. In this review, we abstain from discussing the efficacy or effectiveness of homeopathic medicinal products. The aim of this article is to assess the material risk of homeopathic medicines.

Risk depends on toxicity, exposure, and the latency period. The concept of toxicodynamics and toxicokinetics requires molecular interactions between a substance and parts of a living organism to bring about a chemical or physical effect or to cause a chemical reaction. Therefore, our focus is on the material risk of homeopathic medicinal products, following the paradigm of the Swiss physician Paracelsus: "What is there that is not poison? All things are poison, and nothing is without poison. Solely the dose determines that a thing is not a poison" [2].

Mother tinctures can be approved as herbal medicinal products and/or as homeopathic medicinal products [3]. Within the framework of drug approval in Europe, mother tinctures are of special interest because they bridge the barrier between general toxicological principles of drug assessment and the theoretical constructions of safety assessment as practiced for homeopathic medicinal products by regulatory bodies.

The safety standards for herbal medicinal products in Europe do not differ from the standards applied to chemically defined active ingredients. The same safety standards should be applied to all medicinal products. From the viewpoint of experimental toxicology, mother tinctures contain the highest concentration of the ingredients intended for human homeopathic use. If a satisfying safety profile for a mother tincture can be established, all solutions thereof should be regarded as toxicologically nonhazardous.

\section{Work Plan}

The current review was undertaken to elucidate the following four research questions:

1. What can we deduce from human side effects documented in meta-analyses and in individual randomized controlled trials (RCTs)?

2. Which preclinical and human-use data should be taken to define the safety profile of homeopathic medicines?

3. How to translate data from experimental toxicology into human safety?

4. What do we learn from adopting the concept of impurities to the material risk of homeopathic drugs?

\section{Methods}

This is a narrative review that includes scientific research as well as regulatory texts and was based on a database search amended by a manual search. First, a bibliographic search was conducted by a professional librarian using the largest biomedical and pharmacological database EMBASE. We limited the search to the period from January 1974 to September 2018. For the search strategy, the following search terms were chosen: (homeotherap* or homeopath* or mother tincture* or complex homeopath*, homeotherap* or homeopath* complex, homeotherap* complex) or homeopathy/ or homeopathic agent/ (11,091 hits). The following limits applied: limit to study type (clinical trial or randomized controlled trial or controlled clinical trial or multicenter study or phase 1 clinical trial or phase 2 clinical trial or phase 3 clinical trial or phase 4 clinical trial or evidence-based medicine 
or meta-analysis or "systematic review") [1,962 hits]; limit to year of publication (2007-2019) [934 hits]; limit to language ( $\mathrm{lg}=$ English or $\mathrm{lg}=$ German) [918 hits]. Thereafter, a manual search of the bibliographies of included articles focused on RCTs with mother tinctures and complex homeopathic remedies containing at least one mother tincture or D2 dilution and providing quantitative and qualitative descriptions of the side effects. In homeopathy, the use of mother tinctures or complex homeopathic preparations containing mother tinctures or D2 dilutions under controlled conditions is most suited to show clinical evidence of material risks. In addition, a comprehensive review of the appropriate laws and regulations was performed.

Narrative summaries of the findings are provided according to the research questions.

\section{What Can We Deduce from Human Side Effects Documented in Meta-Analyses and Individual Randomized Controlled Trials?}

\section{Material Risk versus Nonmaterial Risk}

A material risk can only manifest after the interaction between a substance and the biological structures relevant for the effect at a molecular level. Nonmaterial risks occur without such metabolic interaction. In clinical trials, placebo effects and nocebo effects occur in shamtreated patients and are nonmaterial effects. For treatment results in individual patients, it is impossible to distinguish these different modes of actions from each other. Adverse placebo effects are often disease- and treatmentspecific, which means that the person taking placebo may experience something along the lines of what she or he expects to happen. A person's expectations with regard to the placebo help to change the symptoms or the way the person perceives the symptoms [4]. In this context, placebo effects relate to positive expectations, and nocebo effects relate to negative expectations; none of the effects demonstrate any material risks, since the mode of action is a psychoneurologically transmitted adverse experience without any toxicodynamic drug effect.

The involved neurobiological processes have been described in some detail for many diseases and treatments. It is known that they can represent both strength and vulnerability during a disease as well as in response to a therapy. The same concepts discussed for placebo effects (patient expectation or expectations from clinical staff, Pavlovian conditioning, activation of the brain reward circuitry, and anxiety mechanisms) are the basis to frame nocebo effects. Inert substances, plain imagination of substances, or sham treatment bring about negative symptoms in patients [5]. Psychoneurological responses can trigger different neurobiological systems, change per- ceptions and cognitive interpretation, and bring forward nonmaterial nocebo effects [6].

Hall et al. [7] reviewed the evidence that neurotransmitters mediate placebo effects and that genetic variations in these pathways can modify placebo responses. In 2018, Zion and Crum [8] proposed a complex interaction for better understanding placebo effects. Mind framing leads to psychological processes activating neurobiological mechanisms that can result in nonmaterial adverse events. Nocebo effects are the interaction of possible drug effects with neurophysiological mechanisms, psychological processes (implicit learning, expectations, and mindset), influences from social environment, and contextual factors, e.g. patient-health professional relationship.

The findings that mind framing leads to neurotransmitter-mediated placebo effects offers a modern interpretation of the earlier research by Weihrauch and Gauler [9]. Mind framing depends on patient settings, illness, and therapeutic intervention. This discovery underlines the limits for general conclusions drawn from the pooling of safety data from studies with different therapeutic interventions and/or different indications.

Following this recent concept, placebo effects are an integrated part of active drug and placebo medication as well as of social factors. This concept offers a potential explanation for nonmaterial adverse events associated with homeopathy due to mind framing and neurobiological mechanisms [8]. A risk means a significant potential for harm that a reasonable person would want to consider when deciding about undergoing a medical treatment [10]. Information and education on diagnosis and treatment, clinical symptoms, and possible side effects can lead to unwanted nonmaterial effects [11]. Depending on the setting of the patient, nonmaterial risks could be more frequent and more important than the yet unquantifiable but at least rare material risk of homeopathic remedies. Material risks due to drug treatment are adverse effects resulting from toxicodynamic actions of the drug after contact of the medication with the body. To develop material drug harm, an interaction between the components of the drug and the body systems is necessary. Without this interaction, no material risk can occur [12].

\section{Material Risk of Homeopathic Medicinal Products}

Meta-Analyses and Safety

A meta-analysis is usually done to combine the efficacy results of several clinical trials using the same disease and treatment. Meta-analyses on homeopathy tend to combine different homeopathic treatments of different diseases because of the limited number of well-designed and reported original studies.

The frequencies of side effects reported in the review by Mathie et al. [13] are generally low in the placebo groups as well as in the drug-treated groups. No homeopathy-specif- 
ic type or pattern of side effects could be extracted from the data. No correlation between side effects and therapeutic indication became obvious. To investigate tolerability and safety, an explicit hypothesis is needed; thereafter, this hypothesis can be proven in a clinical trial. Without any experimental evidence of toxic effects of homeopathic remedies and without any pattern of material side effects after homeopathic treatment, we are in the process of hypothesis generation. The compiled clinical data do not refer to a research question that should be proven or rejected.

Within these meta-analyses, only the small study (15/15 patients) by Oberbaum et al. [14] who investigated patients with malignant diseases undergoing stem cell transplantation and developing chemotherapy-related stomatitis showed a high incidence of serious complications; no significant difference was found between the placebo group and the group additionally treated with a homeopathic remedy for stomatitis. Main adverse events were grouped as graft-versus-host disease, sepsis, gastrointestinal complications, veno-occlusive disease, and pneumonitis. This pattern shows that adverse reactions do not necessarily correlate with the treatment but with the condition of the patients.

Weihrauch and Gauler [9] were the first to show that side effects not only depend on the medication but also on the underlying disease. They analyzed adverse placebo effects from pooled patient and drug data from a randomized placebo-controlled multicenter trial on five different groups of indications, covering the therapeutic areas of cardiology (nisoldipine), neurology/psychiatry (nimodipine/ipsapirone), metabolism (acarbose), and gastroenterology (hydrotalcite). The frequency and type of placebo-induced adverse reactions vary between indication groups, e.g., tachycardia in controls of cardiac treatment or "dry mouth" in patients with generalized anxiety syndromes. The authors concluded that, as in active treatment, treatment with placebo is frequently accompanied by adverse drug reactions.

In 2017, Mathie et al. [13] published a systematic review on 30 original papers with higher concentrations than D11 (mother tinctures up to D10). We had a closer look at the data and excluded all studies without any numerical reporting of adverse events plus one study with a questionable homeopathic intervention [15]. A total of 1,528 patients remained for our reassessment. 795 patients receiving homeopathic treatment were linked to 75 (9.4\%) patient reports of adverse effects, and 733 patients receiving placebo were linked to $73(10.0 \%)$ patient reports of adverse effects. In this data set, no difference of the frequency of adverse reactions between homeopathic treatment and placebo treatment could be seen (descriptive statistics: Fisher's exact test: 0.73; odds ratio: 1.062, 95\% confidence interval: $0.75-1.51$; relative risk: 1.03 , 95\% confidence interval: 0.85-1.22) [16].
In 2016, Stub et al. [17] did a thorough review and meta-analysis of 41 nonindividualized homeopathic RCTs published between 1955 and January 2011 that included a total of 6,055 participants (nonindividualized homeopathic medicinal products are standardized medicines applied to specific indications). 28 trials reported adverse effects and 5 trials aggravations. The meta-analysis demonstrated that no significant difference was found between homeopathy and control with odds ratio $0.99,95 \%$ confidence interval $0.86-1.14$. The meta-analysis showed that the proportion of patients experiencing adverse effects was similar for both patients randomized to homeopathic treatment and patients randomized to placebo and conventional medicine. This finding was also confirmed for six subgroup settings.

\section{Randomized Controlled Trials and Safety}

A second look on the 5 trials comparing homeopathy versus conventional interventions of the meta-analysis of Stub et al. [17] showed that the study by Witt et al. [18] used individualized classic homeopathy as a comparator.

Stam et al. [19] compared a homeopathic gel (Spiroflor) to capsici compositus FNA (active ingredients: capsicum, glycol salicylate, histamine hydrochloride, and methyl nicotinate) in patients with acute low back pain. The evaluation of safety was based on the difference in the number of patients with adverse events and on withdrawals due to an adverse event and an adverse drug reaction. Adverse events in the homeopathy group were 9/81 versus 19/74 in the group treated with the capsaicin-containing cream. Adverse drug reactions were $3 / 81$ versus $18 / 74$ and withdrawals none versus 8 in the capsaicin group. The authors concluded a better safety profile of the homeopathic treatment because of the lower number of adverse events.

Van Haselen and Fisher compared a topical piroxicam gel with a homeopathic gel (Spiroflor) in patients with osteoarthritis of the knee. For 172/184 enrolled patients, the main efficacy end point pain showed improvement during the investigation [20]. The homeopathic gel was at least as effective as the piroxicam gel. The homeopathic group had 12 adverse events (5 withdrawals) compared to 16 adverse events ( 9 withdrawals) in the piroxicam group; 18 events involved a local reaction (7 homeopathy group, 2 withdrawn; 11 piroxicam group, 5 withdrawn). Local reactions after topical treatment are another example for an indication (and treatment)-specific adverse event pattern.

In 1998, Weiser et al. [21] compared betahistine with a homeopathic remedy in a controlled, double-blind, "double-dummy" technique to match placebos and corresponding active remedies in taste. Treatment was 15 drops/ 3 times daily for 42 consecutive days. 59 patients were allocated to homeopathy (Vertigoheel) and 60 to be- 
tahistine treatment. In 31/119 patients, 29 adverse events were reported in the homeopathic group and 28 in the active controls. Specific adverse events were rare: nausea and tremor of the hands in the homeopathy group and headache combined with vertigo in the betahistine group. The authors concluded that more than $90 \%$ of the patients had good or excellent tolerability of both active treatments.

In 1999, Weiser et al. [22] published a randomized equivalence trial comparing a complex homeopathic nasal spray combining Luffa operculata, Galphimia glauca, histamine, and sulfur (Luffa comp.-Heel) with a cromolyn sodium spray in patients with seasonal allergic rhinitis/hay fever. A total of 146 patients received $0.14 \mathrm{~mL} 4$ times daily for 42 consecutive days. Improvement of symptoms was reported to be quick and lasting, independently of the medication applied, resulting in nearly complete remission of symptoms. Adverse systemic effects did not occur. Local adverse events were protocolled in 3/146 outpatients. The authors concluded the homeopathic spray to be as efficient and well tolerable as the conventional therapy with cromolyn sodium.

What are the shortcomings of the 4 studies used in the risk comparison between homeopathic treatment and conventional therapy to generalize a similar risk in both groups? None of the studies included a placebo arm. Only placebo effect rates provide a direct comparison between patients treated with an active agent and an inactive treatment.

Only the study by Weiser et al. [21] in patients with vertigo used a systemic application, the others used local application $(2 \times$ skin, $1 \times$ nasal mucosa). The data used by Stub et al [17]. are not representative for an overall comparison between homeopathic remedies and conventional allopathic medicinal products because the main mode of application (oral route) was represented only by one trial.

The trials reported in the meta-analysis by Mathie et al. [13] did not show any overall differences in the frequencies of adverse events between homeopathic treatments and control groups. Therefore, we carried out the EMBASE literature search that finally resulted in only 4 studies fulfilling all requirements.

Homeopathy was either applied as the only active principle or as an add-on therapy. The studies had a control group receiving placebo or another active treatment. Although patients receiving active treatment in addition to homeopathy do not directly contribute to the assessment of safety, they are still important for comparison.

Thinesse-Mallwitz et al. [23] reported on an RCT with an add-on of a complex homeopathic combination (Influcid) in the treatment of feverish upper respiratory tract infections. Patients received either on-demand symptomatic standard treatment (paracetamol, ambroxol, and/or oxymetazoline) or homeopathic medication for 7 days plus the same on-demand standard treatment. A subanalysis of the children within this study was published by van Haselen et al. in 2016 [24].

$29 / 265$ (10.9\%) patients in the group treated with addon homeopathy and $35 / 258(13.6 \%)$ patients in the control group experienced at least 1 adverse event. 85 single adverse events were recorded. All adverse events were assessed as nonserious. Because of the complex study design, an allocation of any adverse event to a specific individual drug must be taken cautiously. The group with add-on homeopathy had 1 case of upper abdominal pain, 1 case of asthenia, and 1 patient with vomiting. The control group had 2 cases of nausea and 1 case each of diarrhea, dry mouth, gastroesophageal reflux disease, nasal dryness, rash, and visual impartment. Six patients in the add-on homeopathy group and 11 patients of the controls were withdrawn from the study because of adverse events classified as complications that needed to be treated with antibiotics, glucocorticosteroids, immunomodulators, antihistamines, or antiviral drugs. The findings showed no differences in the pattern of adverse events between the two compared groups. Unwanted drug effects were primarily gastrointestinal complaints or related to the reason for treatment, i.e. respiratory tract infections or exacerbations thereof.

Friese and Zabolotnyi [25] reported on a 10-center, double-blind, placebo-controlled trial in adult patients with acute rhinosinusitis that randomized 72 patients to the active agent group and 72 patients to the placebo group. The active drug was the complex homeopathic remedy (Cinnabaris Pentarkan $\mathrm{H}$ ) that consists of Cinnabaris D3, Echinacea D1, Hydrastis (orangeroot) D3, and potassium dichromate D3. $100 \%$ of patients on active therapy rated tolerability as excellent or good, $29 \%$ of controls as moderate or poor. The only documented adverse event was a patient receiving placebo who had a cough for 2 weeks. Only 1/144 patients experiencing an adverse event is far below the expected frequency and points towards a study focus on possible efficacy and less on tolerability.

Beer et al. [26] published a paper on an RCT investigating the effectiveness and safety of a complex homeopathic drug (Lymphdiaral Basistropfen containing Calendula mother tincture, Condurango D2, Phytolacca D2, Carduus marianus D1, Lycopodium D2, Chelidonium D2, and arsenicum album D8 and mother tinctures of $\mathrm{Hy}$ drastis, Leptandra, Taraxacum, Echinacea, and Sanguinaria) for the treatment of chronic low back pain in comparison to placebo treatment for 105 days. The dosage was $3 \times$ daily 10 drops of active drug or of a placebo solution of identical color and taste, consisting of an $86 \%$ aqueous ethanolic solution masked with saccharum tostum and riboflavin-phosphate sodium. The authors re-
Habs/Koller 
ported headache and gastrointestinal discomfort as the most prominent adverse events in both groups. Exacerbation of fibromyalgia in 1 patient and knee contusion in another patient were reported as serious adverse events during active treatment in addition to 2 cases of erythema and 1 patient each with pruritus, urticaria, and fibromyalgia. No difference in the frequency of adverse events between patients treated with active drug or placebo could be established. The sample size did not allow to show these adverse events to be drug-related, considering that both clinical signs are very common in the German population $[27,28]$. All other adverse event reports were infrequent or singular episodes.

This investigation does not provide any evidence for material adverse drug events of the complex homeopathic remedy or adverse reactions linked to the investigated indication chronic low back pain.

In 2011, Pach et al. [29] published a placebo-controlled RCT comparing local subcutaneous injections of the complex homeopathic remedy Disci/Rhus toxicodendron compositum with placebo and no treatment in patients with chronic low back pain. The active medicinal product is composed of 11 different homeopathic dilutions. $\mathrm{Pa}$ tients were randomly allocated to three groups: subcutaneous injections into painful sites with active agent or placebo and a group without treatment (paracetamol rescue pain treatment on demand only). 37/50 patients in the active drug group and 34/43 in the placebo group reported at least 1 adverse event. In the drug-treated group, 8 patients showed hematoma at the injection side (placebo treatment 5 patients). A common cold was reported for 9 patients with active treatment and for 5 patients in the placebo condition. Unspecified pain was reported for 17 patients in each treatment group. No safety data were recorded for control patients without local treatment. The authors concluded that no differences had occurred between the two intervention groups.

Hematoma at the injection site was a result of the medical intervention but probably unrelated to the injected ingredients. The pattern of adverse events can be interpreted as indication (and treatment) dependent, without any evidence for a material risk associated with the ingredients of the complex homeopathic product. All patients could have been exposed to a seasonal risk of common cold because the main trial period was during fall and winter.

During the literature survey, we came across a publication by Poruthukaren et al. [30]. In an uncontrolled design, Viscum album mother tincture was investigated for antihypertensive properties. At the end of the study period, blood samples of $11 / 41$ patients had shown elevated myocardial creatinine kinase levels $(>24 \mathrm{U} / \mathrm{L})$ without any clinical signs of cardiac or musculoskeletal discomfort. After 2 months of washout, all elevated values had shown a marked drop (no further details evaluable). The finding could be interpreted as a specific material toxic risk of the applied $V$. album mother tincture. Without blood chemistry, it would not have been noted.

\section{Summing Up I}

Clinical trials are primarily designed to show efficacy but are not powered to quantify safety. As a rule of thumb for new chemical entities, the recommended number of patients treated before drug approval is 1,000 [31]. The number of homeopathic patients studied in comparison to conventional therapy is insufficient to allow any final statement. Pooling data from different studies is of very limited value. Different indications ignore the impact of nonmaterial nocebo effects. If any material risks exist, the pooling of different homeopathic remedies implies dilution of specific side effects by increasing the background noise. Meta-analyses of controlled clinical trials with nonindividualized homeopathic treatments do not and cannot distinguish between material harm and nonmaterial placebo and nocebo effects. Placebo and nocebo effects depend on the disease under investigation as well as on the setting of the individual trials. Simplified conclusions resulting from pooling and comparing the frequencies of side effects ignore the current knowledge on the nature of drug-like effects without any drugs [8]. Reported clinical side effects of homeopathic treatments are the sum of nonmaterial and material side effects; the material risk is therefore overestimated when reported side effects are equated with the result of material risks.

There is no clinical evidence for a material risk of nonindividualized homeopathic treatments investigated in controlled trials. This fact holds true for clinically investigated mother tinctures, for less diluted remedies, and for complex homeopathic drugs. No treatment-specific pattern of homeopathy-associated adverse events could be found. In some trials, reported side effects in the treatment and the control groups are linked to the investigated indication pointing towards nonmaterial nocebo effects. However, generally speaking, absence of evidence is not the ultimate evidence of absence [32]. Therefore, although we cannot see any evidence for a material risk due to nonindividualized homeopathic treatment, this lack of evidence does not prove from a formal point of view that this risk does not exist. However, if such a risk exists, it should be neglectable compared to widely accepted health risks and to daily risks of living.

\section{Which Preclinical and Human-Use Data Are Useful to Define the Safety Profile of Homeopathic Medicines?}

In a first step, regulatory toxicology starts to assess the toxicity of a compound by investigating its acute, subacute, and long-term toxicity. The principle of dose-re- 
sponse relationship means that the higher the dose, the more frequently (in an exposed population) and the more severe (in an organism) toxicity will manifest. Risk can be defined as a product of probability and the amount of damage.

An exemplary investigation is the study by Singh et al. [33] on mother tinctures of Ricinus communis, Rauwolfia serpentina, Bellis perennis, Curcuma longa, Terminalis arjuna, and Tribulus terrestris according to OECD guidelines [34]. In rats, the acute toxicity of a single oral dose was established to be $>4 \mathrm{~mL} / \mathrm{kg}$ body weight. The 28 -day oral toxicity study with daily doses of $4 \mathrm{~mL} / \mathrm{kg}$ did not lead to any changes in body weight, in hematological and biochemical parameters, or in the histopathology of the kidneys and the liver. The same research group extended their research to ferrum phosphoricum $3 \times, 6 \times$, calcarea phosphoricum $6 \times$, and magnesium phosphoricum $6 \times$. The homeopathic dilutions were tested in rats for acute, subacute, and long-term effects ( 180 days) after oral dosing. The authors concluded the acute toxicity to be $>2,000$ $\mathrm{mg} / \mathrm{kg}$. No signs of toxicity were found after 28 days and 180 days with respect to body weight development, organ weights, biochemical parameters, hematological parameters, and histopathology of the kidneys, liver, brain, testes, ovaries, and the heart. It was concluded that these mineral-based homeopathic drugs are considered safe as no adverse effects were found in the biochemical, hematological, and histopathological investigations [35].

The lessons learned from this type of investigations is that in principle the toxicity of active substances including homeopathic drugs can be studied through experimental investigations in vivo (and in vitro) by choosing sufficiently high concentrations of the test material and by applying standard procedures accepted in regulatory toxicology.

If no preclinical studies have been published for specific homeopathic remedies, are there other ways of approaching a toxicological assessment?

Frequently, homeopathic starting material is known from other applications, e.g. herbal medicinal products or food. Substances known from other usage include vegetables, e.g. artichokes/Cynara scolymus, meat products, e.g. octopus' ink/sepia succus, spices (caraway/Carum carvi), minerals (natrium chloratum), stimulating food (e.g., coffee), and herbal medicinal products.

When the safety profile of homeopathic starting material from other uses has been accepted because of European tradition or for traditional foods from third countries through a safety assessment by the European Food Safety Authority (EFSA) [36], it should also be regarded safe for homeopathic remedies.

Sometimes safety can be estimated by showing traditional use of a starting material in surprising usage, e.g. Lycopodium clavatum as a release agent in tablet manufacturing [37]; thus, creative literature surveys may be helpful to avoid new animal studies by data mining. In general, if the safety of the starting materials for homeopathic remedies has been established by other usage data, these data should be translated to the safety profile of the corresponding homeopathic remedies to clear homeopathic medicinal products from toxicological suspicion.

Today, by choosing the right candidate and editing the existing knowledge in an appropriate manner, one should be able to build the platform for the safety assessment of a homeopathic medicinal product. Syzygium cumini is a good example for proving this point.

All parts of the Jambolan tree (S. cumini) have a long tradition in folk medicine. In India and other parts of the world, reviews on its medicinal use in a variety of diseases have been documented for more than 100 years, among them blisters in the mouth, cancer, colic, diarrhea, digestive complaints, dysentery, and hemorrhoids [38]. Medicinal preparations of S. cumini for diabetes have shown hypoglycemic effects in different preclinical models and in some controlled clinical trials [39, 40].

In 2017, Bandiola et al. [41] reviewed 6 acute and 2 subacute toxicity studies with different methanolic extracts of leaves, seeds, barks, and roots in rodents. Overall, these studies demonstrated the extracts to be well tolerated in doses exceeding $500 \mathrm{mg} / \mathrm{kg}$. In most of the tests, no specific signs of toxicity occurred, even in doses exceeding $2 \mathrm{~g} / \mathrm{kg}$. These findings are in line with the results by Prasad et al. [42] who reported the acute $\mathrm{LD}_{50}$ of a methanolic extract of $S$. cumini stem bark in rats to exceed $>5 \mathrm{~g} / \mathrm{kg}$. Silva et al. [43] summarized findings that leaf extracts of S. cumini did not exert any acute or chronic effects by oral administration up to 180 days of treatment.

In 2015, Sekar et al. [44] described an ethanolic extract of S. cumini to be nonfatal but to induce histological signs of liver inflammation and fibrosis in 18 rats treated for 28 consecutive days with doses from 1,250 , to 2,500 and $5,000 \mathrm{mg} / \mathrm{kg}$.

Taken these studies together, safety-relevant documentations provide profiles of different preparations derived from S. cumini to show suitability for human use.

In 2018, a pharmaceutical manufacturer started a relaunch of $S$. cumini, for which market approval has been available since June 1997 [45]. The product is offered as a phytoremedy with the over-the-counter indication of adjuvant treatment of diabetes granted by the German regulatory authorities. This preparation contains a $70 \%$ ethanol extract of the S. cumini fruit. The German Homeopathic Pharmacopoeia (HAB 2010) includes a monograph on S. cumini for dried fruits (HAB 2014). Its use is restricted to patients over 18 years because of its ethanol content, and it should not be used during pregnancy and lactation [45].

This example shows that the documented set of toxicological data available for several hydroalcoholic ex- 
tracts of S. cumini today and the experience with the mother tinctures of $S$. cumini corresponding to the German Homeopathic Pharmacopoeia have satisfied the German regulatory bodies to grant market approval and to tolerate the positioning as a modern phytoremedy for a homeopathic medicinal product.

\section{Summing Up II}

Preclinical studies of starting materials or mother tinctures generate findings that can be used for the risk assessment of homeopathic drugs. Independently of the data sources, preclinical documentations and studies resulting in a satisfying toxicity assessment of mother tinctures used in phytotherapy or homeopathy allow market access for these formulations as well as for lower concentrated homeopathic remedies of the same starting material. Moreover, translating study results from other usages for the safety assessment of products utilized in homeopathic medicines has been shown to be successful.

\section{How to Translate Data from Experimental Toxicology into Human Safety? Modulations and Safety Factors}

Starting material of homeopathic remedies can produce several forms of (experimental) toxicity, reaching from acute toxic effects (including death) to chronic toxicity (including cancer). Acute intoxications are the result of an overload of metabolic detoxification pathways and, if severe, this can have longer-lasting secondary consequences such as organ failure. These effects are reasonably well understood and show a dose threshold. The parameters that influence the shape of the dose-effect curve include metabolic activation and inactivation of ingredients, DNA repair, cell cycle control, apoptosis, inflammation, and control by the immune system. Even in carcinogenicity, but only when threshold levels are exceeded, critical steps in the mechanism ultimately leading to cancer become active, and protection mechanisms fail.

The value of animal use in the field of regulatory toxicology relies on a codified set of highly standardized acute, repeated-dose, long-term animal studies, many of them developed in the 1960s. Their relevance has been scrutinized because of the availability of more modern concepts for predicting human outcome after exposure to xenobiotics [46-48]. For regulatory toxicology, European harmonization and the corresponding legal framework slow down the adaptation to new knowledge.

Different approaches have been suggested to translate doses used in animal experiments to human exposure. This extrapolation procedure needs to consider endogenous and exogenous species-specific differences, such as life expectancy, genetic diversity, basic metabolic rates, toxicokinetics, diets, stress, and exposures to other xenobiotics. In 2005, the US Food and Drug Administration (FDA) [49] has published a guidance document describing the use of standard-specific factors that allow the conversion of animal doses in milligrams per kilogram to human doses in milligrams per kilogram using the body surface area as the common denominator.

Nair and Jacob [50] have published scaling factors to convert animal doses to human equivalent doses based on body surface area, resulting in species-specific factors. The multiplier to transform doses from mice to humans is 0.081 , from rats 0.162 , from hamsters 0.135 , from dogs 0.541 , from rhesus monkeys 0.324 , and from minipigs 0.946 . A dose of $100 \mathrm{mg} / \mathrm{kg}$ for rats would correspond to a dose of $16.2 \mathrm{mg} / \mathrm{kg}$ for humans [50].

Most European regulators favor the margin of exposure approach to translate doses used in animal experiments to human exposure. Safety factors (in general of $10,000)$ are introduced to compensate for the knowledge gap in translating the benchmark dose lower confidence limit of $10 \%$ (i.e., $95 \%$ confidence limit of the lowest dose showing a specific toxic effect in $10 \%$ of exposed animals) in animals to the human situation [51].

\section{A General Remark on Safety Factors}

Safety factors are used to make up for extrapolation uncertainties. Recommended safety factors reflect the broad knowledge deficit to reliably bridge the gap between the results of well-conducted experiments using standardized conditions and the human situation. The precautionary principle in health policies always asserts conservative risk prevention schemes to overcome scientific uncertainty [52].

In regulatory toxicology, we assume threshold doses for most toxic effects [53] and no threshold doses for genotoxic carcinogens [54] and ignore hormesis [55, 56]. It is conceivable that low dose responses will be incorporated in toxicological standard research. However, without any sufficient data generation, hormetic concepts lag behind expectations in regulatory toxicology and are thus not incorporated in safety assessments today.

\section{The Role of Heads of Medicinal Agencies/}

Homeopathic Medicinal Product Working Group

The Homeopathic Medicinal Product Working Group (HMPWG) has been established by the Heads of the Medicinal Agencies in Europe. It is dedicated to homeopathic medicinal products for human and veterinary use. The aim is to create a forum for the exchange of regulatory and scientific expertise regarding the assessment of the quality, safety, and use of homeopathic medicinal products in the European Union by publishing harmonized guidance documents. The HMPWG is composed of representatives from the National Competent Authorities and vet- 
erinary representatives. Representatives of the European Commission (EC), the European Medicines Agency (EMA), and the European Pharmacopoeia can attend all meetings of the HMPWG (www.hma.eu, accessed January 2019).

The HMPWG has established the concept of first safe dilution (FSD) for homeopathic products and consolidated a growing list for individual starting materials on a case-by-case level [57]. The points to consider on nonclinical safety of homeopathic medicinal products are laid down in the Rules of Procedure for the HMPWG, adopted in 2007 [58]. The key mission of the working group is to provide guidance for the competent authorities and applicants of homeopathic medicinal products, to harmonize dossier templates for registrations throughout the European Union, to prepare guidance documents, and to draft rules of procedure for approval by the Heads of Medicines Agencies. The procedure to establish an FSD has been published by the Heads of Medicines Agencies in 2016 [59].

FSDs are calculated for oral preparation as a reference for further calculations, e.g. conversion to other pharmaceutical forms. The listing of FSDs comprises the name of the stock (raw/starting material) and the reference to a monograph in the European Pharmacopoeia and/or an officially used Member State Pharmacopoeia. The listing names the toxic component on which the calculation of the FSD is based or a toxicologically relevant component of the raw material, provided that this component can be quantified (e.g., chemicals). Alternatively, an upper content threshold as specified in monographs of pharmacopoeia or the information from an official regulatory authority document is used (e.g., Committee on Herbal Medicinal Products assessment reports). When the toxicological principle is not quantified in a pharmacopoeial monograph, the whole starting material is used as a calculation basis. The FSD is determined following a decision tree on the criteria for establishing an FSD published by the HMPWG in 2007 [58].

The decision tree starts with the question whether the raw material is a known food or a constituent of food; if the answer is "yes," safety assessment will follow EC food law. If the answer is "no," a phytochemical or chemical characterization is available for the raw material, the maximum amount of the raw material in $10 \mathrm{~g}$ of the product is $\leq 0.15 \mu \mathrm{g} /$ day for lifetime intake, and the product is assessed as safe without any further evaluation. Higher daily allowances may be established if an authorized allopathic medicinal product exists (LHRD approach: lowest human recommended dose divided by 100) or if enough toxicity data are available to calculate a permitted daily exposure (PDE).

The PDE is defined as an estimate of daily human exposure at and below which there is a negligible risk to hu- man health. To convert a PDE into an FSD, a worst-case scenario is used for all calculation steps, implying that the proposed dose of stock is present in $10 \mathrm{~mL} / 10 \mathrm{~g}$ of oral solution or in $10 \mathrm{~g}$ of trituration. This concentration is taken as the reference for further calculations. Calculation of the FSD and the conversion factor for dilution consider the pharmaceutical form, the type of dilution, as well as the different manufacturing methods. For the safety assessment, a reference note will suffice for compounds mentioned in the list of the FSD. In contrast, a detailed analysis is needed for all unlisted compounds or listed compounds intended for use in higher concentrations. Missing study data must be justified by still demonstrating an acceptable level of safety.

In November 2018, the HMPWG published a consolidated list of 167 homeopathic FSDs [57]. Six mother tinctures were accepted as safe: the vegetable onion Allium cepa (according to the French and German pharmacopoeia); the flower Bellis perennis that is a regular part of the diet of grazing animals; the cockroach Blatta orientalis (monograph-specific preparation according to the German pharmacopoeia) that consists of chitin (poly-Nacetyl-D-glucosamine), which is nontoxic according to the Environmental Protection Agency (USA) [60], and Sepia officinalis prepared according to the French pharmacopoeia using the dried ink gland as a starting material. Safe D1 solutions listed in this document are: aurum metallicum prepared according to the European Pharmacopoeia (HAB6 and French Pharmacopoeia), gold is an accepted food additive according to a recent EFSA opinion (2016) [61]; causticum hahnemanni prepared in a special manufacturing procedure from potassium hydrogen sulfate and calcium hydroxide is agreed to be safe because no measurable amounts of potassium or calcium can be expected in a D1 solution. Moreover, Fucus vesiculosus made from bladder wrack and prepared according to the Pharmacopée Française is listed. The iodine content in $10 \mathrm{~g}$ of a D 1 solution ( $10 \mathrm{~g}$ D 1 correspond to 0.02 mg iodine) is below the acceptable amount of iodine for neonates $(0.03 \mathrm{mg} / 3 \mathrm{~kg}$ body weight). Finally, S. officinalis - when using the dried secretion of the gland instead of the dried ink gland prepared according to the German Pharmacopoeia - is safe based on the use as food [57, 62].

So far, the list of decisions on these 167 stocks has shown no homeopathic medicinal product that needs a dilution $>$ D9 to achieve an FSD. Theoretically, if nothing is known on the toxicity of a starting material in the decision tree, the FSD is set at D24 (corresponding to C12), i.e. a dilution of $1: 10^{24}$. For practical purposes, it can be generalized that, in the worst case, no material risk occurs in dilutions $\geq \mathrm{D} 9$ of nonindividualized homeopathic remedies because D9 implies a threshold of toxicological concern (TTC) $<0.15 \mu \mathrm{g}$ of the starting material (cf. next paragraph). Depending on the manufacturing method, it 
can be D7 or D8. A precondition is that production is done according to good manufacturing practice guidelines that equally apply to homeopathic products as well as to conventional medicines and cover the manufacturing process, premises, personnel, packaging, and labeling.

The $1.5 \mu \mathrm{g} /$ person/day value was already derived by Munro et al. in 1996 [63]. In 2001, Barlow et al. [64] reported that sensitive end points such as immunotoxicity, prenatal toxicity, neurotoxicity, and developmental toxicity would probably also be covered by this limit value because of the large uncertainty factors built into this model. The EMEA guideline on the assessment of genotoxicity of herbal substances/preparations sets a limit value of $1.5 \mu \mathrm{g} /$ day for substances with a structural alert for genotoxicity (2008) [65]. The same limit value is set for residues with structural alerts for genotoxicity contained in medicinal products by the EMA guideline on setting health-based exposure limits for use in risk identification in the manufacture of different medicinal products in shared facilities (2014) [66]. The HMPWG approach for FSDs is more conservative and results in $0.15 \mu \mathrm{g} /$ person/ day, regardless of whether the substance is genotoxic or not.

\section{Setting TTCs}

Already more than 20 years ago, Munro et al. [63] established the principle that a dose exists for any substance below which there is no biological activity and thus no toxicological concern. The relationship between chemical structure and toxicity was explored through the compilation of a large reference database that consists of over 600 chemical substances tested for a variety of end points, resulting in over 2,900 no-observed-effect levels. Each substance in the database was classified into one of three structural classes using a decision tree approach [67]. The resulting cumulative distributions of no-observed-effect levels for each of the structural classes differed significantly from one another, supporting the contention that chemical structure defines toxicity. The database was used to derive a threshold of acceptable human exposure for each of the structural classes that could be applied in the absence of specific toxicity data on a substance within one of the three structural classes. Human exposure thresholds provide guidance on the degree of testing and evaluation required for substances that lack toxicity data. Based on the concept by Munro, several groups have broadened and refined the database. A recent example is the incorporation of cosmetics-related chemicals that expands the chemical space and provides more robust threshold values [68]. A regularly updated open-access decision tree is available [69, 70]. Since Cramer classes have been developed in recent years with the toxicological knowledge of the 1980s, the need to refine some steps in the original decision tree has been stressed, but the basic principles of Cramer's and Munro's works are still valid [68].

In 2014, Buchholzer et al. [71] published current concepts on the safety assessment of active homeopathic substances. This publication was intended to further develop and clarify the practical use of several assessment routes, which includes the following approaches and/or assessment strategies: lowest human recommended dose (LHRD/100), nonclinical data set and limit values such as PDE, accepted daily intake, tolerable daily intake, reference dose, TTC, food regulation, and unavoidable background exposure.

The authors state that homeopathic remedies have a centuries-long tradition and their availability and application is widespread worldwide. According to the Directive 2001/83/EC 2001, the raw materials conventionally used in homeopathic medicinal products are basically regulated according to the same nonclinical safety principles as applied to other human medicinal products. The authors conclude that calculations assuming a usual dosage of approximately $1 \mathrm{~mL}$ or $1 \mathrm{~g}$ (dilution or trituration) daily of the finished homeopathic medicinal products are based on sufficiently conservative assumptions. In contrast, HMPWG provides a daily dose of $10 \mathrm{~g}$ or $10 \mathrm{~mL}$ [58].

In their 2019 paper, Buchholzer et al. [1] compiled a list of acceptable amounts per day for 173 homeopathic raw materials used in Germany. The authors provide guidance for stakeholders with a focus on the German market. A huge number of the assessed substances are not part of the FSD list. Most of the substances that are in the FSD list adopt the principles and position of the HMPWG, but sometimes their assessments are stricter, sometimes less strict. In these cases, it becomes clear that different evaluation standards were used. Thereby, the guidance document reflects the scientific view of the persons responsible for licensing homeopathic medicinal products through the Federal Institute for Drugs and Medical Devices in Germany. The acceptable amounts per day are given in micrograms per kilogram body weight per day or as the "amount in daily dose of lowest possible homeopathic preparation" if based on insufficiently specified food data. Without a priority ranking of the applied evaluations (food regulations, background exposure, lowest regulatory recommended human doses, threshold of toxicological concern approach, and regulatory limit values), individual assessments have been based on scientific expert judgment. Explanatory notes and annotations help to comprehend the assessment and refer to previous decisions.

Hartung [72] published a comprehensive review on the concept of TTCs. Risk assessments are based on defined doses (with and without the incorporation of uncertainty factors) below which nothing happens in test ani- 
Table 1. Stricter regulations for homeopathic remedies than for human exposure by other origins

\begin{tabular}{lll}
\hline Homeopathic preparation & Comparator & Ref. No. \\
\hline Plumbum metallicum & Lead exposure through drinking water & $58,77-83$ \\
Atropa belladonna & Allopathic medicines in USA and Canada & $57,89-92$ \\
Secale cornutum & Food and feed contaminations & 96,97 \\
\hline
\end{tabular}

mals. Starting from these defined animal doses, human lifetime daily exposure doses are calculated that are extremely unlikely to have any effects in humans (by again applying safety and uncertainty factors). This is a pragmatic way to transfer limits of exposure for untested chemicals based on experimental data available for a group of chemicals. In a real-world scenario, the probability of hazard at some point simply falls below the noise, i.e., the inevitable spontaneous development of such diseases. The TTC approach becomes suspicious in the case of chemicals and starting materials for which little or no toxicological reference data exist or for which the validity of the database is questionable. In general, regulatory approval based on the TTC approach is rather limited with three exceptions: the HMPWG approach towards homeopathic medicinal products, low-level food constituents (food packaging migrants and flavoring agents) [73], and drug impurities (genotoxic impurities in pharmaceutical preparations and genotoxic constituents or contaminations in herbal preparations) [74]. The considerable interest and emerging consensus of European Agencies might offer the opportunity for the broader application of the TTC approach. TTC databases may help at least with priority settings or to decide whether exposure to a substance is so low that the probability of an adverse health effect is neglectable. Then, animal tests become unnecessary.

In Canada, approximately 1,500 substances occurring in the environment have been identified for priority human health risk assessment. In September 2016, the Government prioritized 237 of these substances, and 89 were found to be associated with direct or indirect exposure lower than their associated TTC values. Therefore, these substances were not considered to be of concern to human health at the current levels of exposure and were thus excluded from further assessment [75].

The best way to replace the safety factor is to substitute uncertainty by knowledge. If the industry targets FSDs for less diluted homeopathic medicinal products, this goal can be achieved by safety documentation and toxicity studies.

A pragmatic strategy for the material risk assessment of homeopathic remedies is to establish a general limit for dilutions above which no concerns of material toxicity are expected. This goal can be achieved without any knowl- edge of the toxicity of the starting material by the development of TTC values based on Munro and Cramer classes $[63,67]$. With an adequate set of toxicological data, and under consideration of the instructions for use of the individual product, lower dilutions of individual homeopathic medicines than those calculated with TTC can be justified.

\section{Summing Up III}

When translating experimental toxicological results into expected results of human exposure, a broad variety of differences must be considered. None of the proposed assessment methods for deriving at safe exposure limits for toxic effects for humans from experimental drug safety data is perfect. All safety assessment concepts target the minimization of possible side effects in patients by following precautionary principles. The most appropriate and reliable translation method should be chosen by cross-matching exposure data from other sources and by using preclinical and clinical information on the compound of investigation and related materials. For homeopathic remedies, the aim is to establish an acceptable daily intake limit in the absence of sufficient human use data. The TTC approach should be an integrated part of priority setting and risk assessment for homeopathic remedies.

\section{Adopting the Concept of Impurities to the Material Risk of Homeopathic Drugs}

Impurities in pharmaceuticals are unwanted chemicals that remain from starting materials or develop during formulation or upon aging of the active ingredient or the formulation. The presence of these trace amounts of unwanted materials may influence the efficacy and safety of pharmaceutical products. Improved analytical sensitivity strengthens the need to regulate impurities in medicinal products. Thus, the International Conference on Harmonization $(\mathrm{ICH}, 2006)$ has formulated guidelines regarding the control of impurities [76].

Three examples are given to show that safety standards for homeopathic products can be stricter than any thresholds otherwise applied to maintain human safety standards (Table 1). 
The Case of Plumbum Metallicum: Different Safety

Standards for Homeopathic Preparations and

Drinking Water

Lead $(\mathrm{Pb})$ is a naturally occurring metal found in the Earth's crust. Lead is a cumulative toxicant that affects multiple body systems. Environmental lead exposure results from ingestion of lead-contaminated dust, water, and food [77]. The provisional tolerable weekly intake of $0.025 \mathrm{mg} / \mathrm{kg}$ body weight (b.w.) was withdrawn in 2011 [78].

The council directive $98 / 83 / \mathrm{EC}$ on the quality of water intended for human consumption has the aim to protect human health from adverse effects resulting from a lifetime use of water. In January 2013, a further reduced limit value of $10 \mu \mathrm{g} / \mathrm{L}$ was set for lead contamination in drinking water that has been transferred into German legislation [79]. In June 2013, the Council of Europe member states adopted Resolution CM/Res (2013) 9 on metals used in food contact materials, and a technical guide became available for its implementation [80]. A legally nonbinding upper threshold for lead from contaminated food has been set to $10 \mu \mathrm{g} / \mathrm{kg}$ food stuff. For a transitional period, a value of $40 \mu \mathrm{g} / \mathrm{kg}$ seems acceptable [81].

In homeopathy, plumbum metallicum (pure lead) and plumbum aceticum (lead acetate containing $54.6 \%$ lead) for instance are used as a starting material. Usually, homeopathic preparations of plumbum are diluted ranging from $\geq \mathrm{D} 6$ up to $\mathrm{C} 200$. The HAB defines the upper limit for D1 trituration of plumbum metallicum with $10 \%$ (range 9.4-10.6) $\mathrm{Pb}$. Market access of plumbum metallicum D1 is prohibited by the German drug law [82]. The Commission D monograph plumbum metallicum names $\mathrm{D} 4$ as the highest concentrated dilution of plumbum metallicum for tinctures and globules, D6 is the highest concentrated dilution without the disclaimer: not to be used in infants, toddlers, during pregnancy, or while breastfeeding [83].

To approximate the daily exposure of patients taking a typical homeopathic dose of plumbum metallicum, the following calculation can be made: $1 \mathrm{~g}$ of globules is around 45 globules (size $5 \mathrm{HAB}$ ). $1 \mathrm{~g}$ of $\mathrm{D} 4$ globules contains $\approx 10 \mu \mathrm{g} \mathrm{Pb}$. A typical standard dose for an adult would be 5 globules 3 times a day. The average weight of a globule is $22.2 \mathrm{mg}$. A daily dose would then correspond to $333 \mathrm{mg}$ globules containing $3.33 \mu \mathrm{g} \mathrm{Pb}$ per adult, resulting in an exposure of $0.067 \mu \mathrm{g} / \mathrm{kg}$ b.w. for a person weighing $50 \mathrm{~kg}$. For a child weighing $10 \mathrm{~kg}$, the daily exposure would correspond to $0.67 \mu \mathrm{g} / 10 \mathrm{~kg}$ b.w.

The average daily intake of tap and bottled water is about $75 \%$ of the total water intake from food and drinking. From the EFSA survey, it is concluded that $1.6 \mathrm{~L}$ for adult women and $1.8 \mathrm{~L}$ for adult men and $1.0 \mathrm{~L}$ for 2 - to 4 -year-old girls and boys are reasonable estimates of daily water consumption [84]. The daily temporary addi- tional lead burden resulting from the usage of "highly concentrated" homeopathic plumbum metallicum remedies is less than $10 \%$ of the burden from daily water intake.

This example demonstrates that the individual lead uptake due to the differences in water drinking habits outweighs by far the lead exposure resulting from the decision to take a homeopathic plumbum metallicum remedy granted a marketing authorization/registration in Germany.

According to the HMPWG list of FSDs [58], the acceptable daily amount for plumbum metallicum is set to $5 \mu \mathrm{g} \mathrm{Pb}$ in $10 \mathrm{~g}$ of the preparation.

\section{The Case of Atropa belladonna: Different Safety}

Standards for Homeopathic and Allopathic Medicines

Belladonna (deadly nightshade, devil's cherries) is a herb that has historically been used for poisoning and in traditional medicine for centuries. The active pharmacological principle of belladonna preparations is an anticholinergic action resulting from the competitive inhibition of acetylcholine. The combination of up to 20 different tropane alkaloids, such as hyoscyamine, apoatropine, and scopolamine (hyoscine), antagonizes the muscarinic action of acetylcholine. Deliberate or accidental poisoning through the ingestion of belladonna alkaloids can be fatal, $10 \mathrm{mg}$ of scopolamine or atropine may be lethal in children. Incorporation of $0.5 \mathrm{mg}$ atropine results in slight cardiac slowing, dryness of mouth, and inhibition of sweating; $2 \mathrm{mg}$ lead to rapid heart rate, palpitation, marked dryness of the mouth, dilated pupils, and blurred vision [85].

Some products labeled as homeopathic may contain marked amounts of ingredients that can cause side effects and drug interactions because of insufficient standards for quality, strength, or purity. The FDA announced in 2017 that laboratory analysis found varying amounts of belladonna in certain homeopathic teething tablets, sometimes far exceeding the amount claimed on the label, and urged consumers not to use these products [86]. No detectable amounts of alkaloids in these homeopathic formulations should have been present. The FDA has investigated serious adverse reactions associated with the use of these teething products. There is an ongoing debate whether the alkaloid amounts found in the laboratory analyses of the US products have been high enough to cause any toxic effects. Without doubt, such misconduct could not happen in the regulatory framework for homeopathic products in Europe [87].

Poisoning may also result from drinking herbal teas contaminated with dried parts of Atropa belladonna [88].

The US Code of Federal Regulations (2017) lists belladonna alkaloids as contained in A. belladonna as overthe-counter cough-cold products [89]. Belladonna alka- 
loids that contain atropine (d,dl-hyoscyamine) and scopolamine(l-hyoscine) are probably safe for oral use at doses used in marketed cough-cold products $(0.2 \mathrm{mg})$. The AHFS monograph Belladonna (updated April 2018) lists mono- and combination products (e.g., with phenobarbital or powdered opium available in the USA) [90]. Allopathic prescription-only products that contain a fixed combination of ergotamine tartrate, phenobarbital, and belladonna alkaloids have been withdrawn from European markets but are still available in Canada $[91,92]$. For example, Bellergal ${ }^{\circledR}$ contains $40 \mathrm{mg}$ of phenobarbital, $0.6 \mathrm{mg}$ of ergotamine tartrate, and $0.2 \mathrm{mg}$ of alkaloids of belladonna. This medicine is prescribed for women with menopause symptoms and nervous tension. The recommended standard dose is 1 tablet twice daily resulting in $0.4 \mathrm{mg}$ belladonna alkaloids.

For homeopathic medicinal products, the starting material is the whole fresh flowering plant, harvested at the end of flowering with the ligneous stems removed [93]. The mother tincture is prepared from the comminuted herbal drug and contains $0.020-0.050 \%[\mathrm{~m} / \mathrm{m}]$ alkaloids calculated as hyoscyamine.

According to the Commission D monograph, D4 is the highest concentration for homeopathic use in dilutions and triturations and D2 in globules [94]. $1 \mathrm{~g}$ D4 contains $0.1 \mu \mathrm{g}$ alkaloids calculated as hyoscyamine. Thus, 120 globules (size $3 \mathrm{HAB}$ ) contain $\approx 0.001 \mu$ g alkaloids. A typical standard dose would be 15 globules or $125 \mathrm{mg}$ globules daily. The daily oral uptake of alkaloids for a person taking a typical dose of belladonna matches $0.000125 \mu \mathrm{g}$. For an adult weighing $50 \mathrm{~kg}$, this amount parallels an exposure of $0.0000025 \mu \mathrm{g} / \mathrm{kg}$ b.w., and for a child weighing $10 \mathrm{~kg}$, an exposure of $0.0000125 \mu \mathrm{g} / \mathrm{kg}$ b.w.

The standard dose prescribed in allopathic use outside Europe translates to $80 \mu \mathrm{g} / \mathrm{kg}$ b.w. for an adult person weighing $50 \mathrm{~kg}$. These recommended doses in allopathic medicines are orders of magnitude higher than those accepted for homeopathic remedies in Europe.

According to the HMPWG List of FSDs [57], the acceptable daily amount for A. belladonna is set to $0.6 \mu \mathrm{g}$ atropine/day in $10 \mathrm{~g}$ of the preparation.

\section{The Case of Secale Cornutum: Different Safety \\ Standards for Ergot Alkaloid-Associated Risks in Food and Homeopathic Medicinal Products}

The alkaloid concentration in ergot varies between $0.01 \%$ and $0.5 \%$ depending on the provenience. In Western Europe, the average total alkaloid concentration (of central European ergot) is set to $0.2 \%$. Consequently, an impurity with ergot of $0.05 \%$ in cereals (maximum content according to good agricultural practices) results in a tolerable total alkaloid concentration of $1,000 \mu \mathrm{g} / \mathrm{kg}$ and in meals with a yield of $75 \%$ in a concentration of $750 \mu \mathrm{g} /$ $\mathrm{kg}$. The maximum allowed impurity with ergot $(0.05 \%=$
$1,000 \mu \mathrm{g}$ alkaloids/kg) was exceeded in harvest samples during the hot and dry summer of 2003 [95].

In 2012, the EFSA delivered a scientific opinion on ergot alkaloids in food and feed [96]. Estimates of chronic and acute exposures for various age groups across Europe were based on the group of ergot alkaloids produced in sclerotia of Claviceps purpurea, the most common Claviceps species within the Hypocreales. A margin of exposure dose was calculated using a 13-week rat feeding study of ergotamine, taking tail muscular atrophy as the representative end point of the vasoconstrictive effects of ergot alkaloids. A BMDL 10 (dose of the lower 95\% confidence limit on a $10 \%$ response [i.e. tail muscular atrophy]) of $0.33 \mathrm{mg} / \mathrm{kg}$ b.w./day was calculated. This reference point was used to establish the tolerable daily intake in humans. The group acute reference dose was set to $1 \mu \mathrm{g} / \mathrm{kg}$ b.w. and the group tolerable daily intake to $0.6 \mu \mathrm{g} / \mathrm{kg}$ b.w./day. The panel concluded that estimates of human exposure to ergot alkaloids suggest a low risk of toxicosis under normal conditions.

How do these food reference values compare to the concentrations of secale cornutum in homeopathic preparations? The HAB monography specifies the content of the group of ergot alkaloids in the sclerotium of C. purpurea calculated as ergotamine at $\approx 0.1 \%$. Thus, the resulting concentration in the corresponding mother tincture is $\approx 0.01 \%$ [97]. The highest recommended dosage found in the relevant homeopathic materia medica is 0.5 $\mathrm{mL}$ of mother tincture in women with hemorrhage of the puerperium after the uterus is entirely emptied or when it fails to contract satisfactorily and in secondary puerperal hemorrhage as the result of incomplete involution of the uterus [98]. Calculating with a b.w. of $50 \mathrm{~kg}$, the amount of ergotamine alkaloids applied is about $1 \mu \mathrm{g} / \mathrm{kg}$ b.w. In many countries including Canada and Germany, preparations of secale cornutum up to the dilution D3 are subject to medical prescription. The upper routine daily dose of secale cornutum D3 is 6 times 5 drops $(\approx 1.5 \mathrm{~mL})$ resulting in an incorporation of $0.03 \mu \mathrm{g} / \mathrm{kg}$ b.w. of ergot alkaloids. Self-medication is restricted to concentrations $\leq 0.003 \mu \mathrm{g} / \mathrm{kg}$ b.w. The threshold set for homeopathic ergot alkaloid preparations is far smaller than the tolerable daily intake given for food contamination.

Foods and drugs are subject to different legal frameworks. The differences observed in the regulation of ergot alkaloids-associated risks in food and homeopathic remedies are striking. Scientifically, one should expect regulatory bodies to follow the same principles and to arrive at comparable assessments. We conclude that comparisons and harmonization in safety standards set for human exposure resulting from different sources are helpful to avoid applying double standards.

The HMPWG has not yet calculated an FSD for secale cornutum. According to the decision tree in the 
HMPWG points to consider [58] and the rules for the FSD calculation (food data in this case), a maximum daily amount of $0.6 \mu \mathrm{g} / \mathrm{kg} \times 3=1.8 \mu \mathrm{g} / 3 \mathrm{~kg}$ b.w. ergotamine in $10 \mathrm{~g}$ of the preparation would be assessed as safe.

\section{Regulations of Active Materials and Impurities Can Lead to Different Safety Thresholds in Homeopathic Remedies}

Toxicity is caused by the ingredient, but the allowed regulatory thresholds depend on the applied regulatory rules. Diluted starting material should not be considered more toxic than identical impurities of the carrier material. Regarding the excipient(s) used and the impurities or degradation products detected in homeopathic remedies, the relevant quality guidelines should be consistent. By comparing the allowed daily maximum intake levels for metals, it becomes obvious that the daily tolerance for impurities in homeopathic remedies is higher than that for declared homeopathic active ingredients (Table 2).

How is it possible that the acceptable daily amount for the lifelong intake of the same substance is assessed differently, depending on its use and declaration?

The acceptable daily amounts of the homeopathic active ingredients copper and iron have been derived from nutritional requirements and dietary intakes of breastfed neonates. The amounts of copper and iron that a newborn receives daily with breastmilk were used by the HMPWG as acceptable daily amounts for calculating the FSD. In contrast, when they are present as impurities in medicinal products, toxicologically relevant data are used for the toxicity evaluation of the same substances.

The toxicological assessments for silver, arsenic, mercury, and antimonite are based on the PDE values of the ICH Q3D guideline [99], except that the HMPWG additionally provides a weight adjustment to a lifelong body weight of $3 \mathrm{~kg}$ for the safety assessment of homeopathic active ingredients.

From a toxicologist's point of view, the dose makes the toxicity and not the mode of declaration for the respective substance.

FSDs are calculated most conservatively (10 g daily, 3 $\mathrm{kg}$ b.w. for lifetime) to provide safe cumulative lifetime doses. FSD calculation incorporates adjustment of the body weight calculation down to an assumed lifelong weight of $3 \mathrm{~kg}$. This procedure contrasts with the EMA/ ICH Q3D guideline [99] stating that permitted daily exposures are considered to be protective of public health for all patient populations. The ICH guideline M7 (R1) on the assessment and control of DNA reactive (mutagenic) impurities in pharmaceuticals describes the concept of less than lifetime exposure [100]. Permitted daily exposure in relation to less-than-lifetime exposure, standard risk assessments of known carcinogens assume that cancer risk increases only as a function of the cumulative
Table 2. Comparison of the allowed maximum daily intake ( $\mu \mathrm{g} /$ day) between active homeopathic ingredients and contaminants, derived from the European Coalition on Homeopathic and Anthroposophic Medicinal Products and European Medicines Agency

\begin{tabular}{lcc}
\hline Metal & $\begin{array}{l}\text { Active homeopathic } \\
\text { ingredient }\end{array}$ & Contaminant \\
\hline $\mathrm{Ag}$ & 9.9 & 150 \\
$\mathrm{As}$ & 0.9 & 15 \\
$\mathrm{Cu}$ & 300.0 & 3,000 \\
$\mathrm{Fe}$ & 300.0 & 13,000 \\
$\mathrm{Hg}$ & 1.8 & 30 \\
$\mathrm{Sb}$ & 72.0 & 1,200 \\
\hline
\end{tabular}

dose. Thus, the cancer risk of a continuous low dose over a lifetime would be equivalent to the cancer risk associated with an identical cumulative exposure averaged over a shorter duration. The TTC-based acceptable intake of $1.5 \mu \mathrm{g} /$ day is considered to be protective for a lifetime of daily exposure. In contrast, for homeopathic active substances, a 10 times lower threshold value has been established if available toxicological data are judged as insufficient, regardless whether the substance is genotoxic or not.

To address less-than-lifetime exposures to mutagenic impurities in pharmaceuticals, an approach is applied in which the acceptable cumulative lifetime dose $(1.5 \mu \mathrm{g} /$ day $\times 25,550$ days $=38.3 \mathrm{mg}$ ) is uniformly distributed over the total number of exposure days during less-than-lifetime exposure. This distribution would allow a higher daily intake of mutagenic impurities than in the case of lifetime exposure and would still maintain comparable risk levels for daily and nondaily treatment regimens. Therefore, in the case of intermittent dosing, the acceptable daily intake should be based on the total number of dosing days [92]. Using the assumptions of this model could help to specifically address possible risks occurring early in life by age-adjusted FSDs. The accepted safety threshold for mutagenic impurities in pharmaceuticals should be a reasonable approach to regulate all homeopathic active substances, independently of the toxic profile of the starting material.

\section{Summing Up IV}

Human safety data are easier to translate to human safety assessment than data from experimental animal and in vitro studies. Experimental data involve less uncertainty than the acceptance of having no data. Risk assessment of homeopathic medicines can be improved through harmonization of toxicological assessment and risk management of active compounds and impurities independently of their use as food and drugs. From an outside perspective, the homeopathic industry could work to- 
gether to broaden the toxicological database for starting materials and mother tinctures and the characterization of their biologically active constituents. Whenever comparisons of safety thresholds result in double standards, this realization implies room for improvement and harmonization.

\section{General Discussion}

\section{Lessons Learned from Clinical Studies}

We conclude that the number of homeopathic patients observed under controlled study conditions is insufficient to come to a final statement. Pooling data from studies with different indications ignores the impact of nonmaterial nocebo effects. If material risks exist, the pooling of different homeopathic remedies implies dilution of specific side effects by increasing this background noise. Meta-analyses of controlled clinical trials with nonindividualized homeopathic treatments do not and cannot distinguish between material harm and nonmaterial placebo and nocebo effects. Simplified conclusions resulting from comparing the frequency of side effects ignore the knowledge on the nature of drug-like effects without drugs.

Risks due to counterfeiting may be a problem in markets with lesser control of homeopathic remedies; however, if avoidable production problems lead to defective drugs, these are quality assurance problems but not inherent properties of the affected drug [101-104]. Alike, replacing an effective conventional treatment with an inadequate homeopathic one presents a risk. This malpractice erroneously changes a medical treatment for the worse but is only indirectly linked to the applied homeopathic medicine. We were unable to quantify this risk, but court cases have shown that these wrongdoings are a real threat [105]. Johnson et al. [106] reported a retrospective observational study which supports the assumption that the use of complementary therapies is associated with reduced adherence to additional conventional cancer therapy, thereby reducing the survival time of severely ill patients.

Disregarding these special situations, there is no clinical evidence for a material risk of nonindividualized homeopathic treatments. This fact holds true for clinically investigated mother tinctures, for less diluted remedies, and for complex homeopathic drugs. No treatment-specific patterns of homeopathy-associated adverse events could be found. Reported clinical side effects of homeopathic treatments are the sum of nonmaterial and material side effects; the material risk is overestimated when reported side effects are equated with the result of material risks.

However, generally speaking, absence of evidence is not ultimate evidence of absence [32]. Therefore, al- though we cannot see any evidence for a material risk due to nonindividualized homeopathic treatment, such absence does not prove from a formal point of view that this risk does not exist. However, if such a risk exists it should be neglectable compared to widely accepted health risks and to daily risks of living.

Pharmacovigilance and postmarketing surveillance are cornerstones of conventional drug safety [107]. For homeopathic products without indication according to Article 14(1) of Directive 2001/83/EC, there are no reporting obligations for suspected adverse reactions or the requirement to submit periodic safety update reports [108]. The waiver of pharmacovigilance reporting for registered homeopathic remedies is in line with our analyses of side effects reported under the controlled conditions of clinical studies and reflects the expectation that no meaningful adverse event signal detection could be obtained against the statistical noise in heterogeneous patient populations.

\section{Lessons Learned from Preclinical Studies and Experimental Results}

Publications of original experimental data generated with the starting materials of homeopathic medicinal products are scarce compared to the up to 8,220 nonindividualized homeopathic remedies available today [109]. There is significant room for improvement by generating new data for yet unexplored starting materials. Experimental toxicological studies of starting materials or mother tinctures allow the generation of specific data that can be used for the risk assessment of homeopathic drugs. Preclinical documentations and studies resulting in satisfying toxicity assessment of mother tinctures used in phytotherapy or homeopathy allow market access for these formulations as well as for lower concentrated homeopathic remedies of the same starting material. Moreover, translating study results from other usages of active compounds of homeopathic products is acceptable for purposes of safety assessment.

Safety factors are used to make up for extrapolation uncertainties. Therefore, safety factors reflect the broad knowledge gap between preclinical results and the human situation. The precautionary principle in health policies always asserts conservative risk prevention schemes to overcome scientific uncertainty [52]. None of the proposed assessment methods of deriving at safe exposure limits is perfect. The most appropriate and reliable translation method should be chosen by cross-matching exposure data from other sources and by using preclinical and clinical information on the compound of investigation and related materials. For homeopathic remedies, the aim is to establish a first safe dilution or an acceptable daily intake limit (TTC) in the absence of sufficient human use data. 


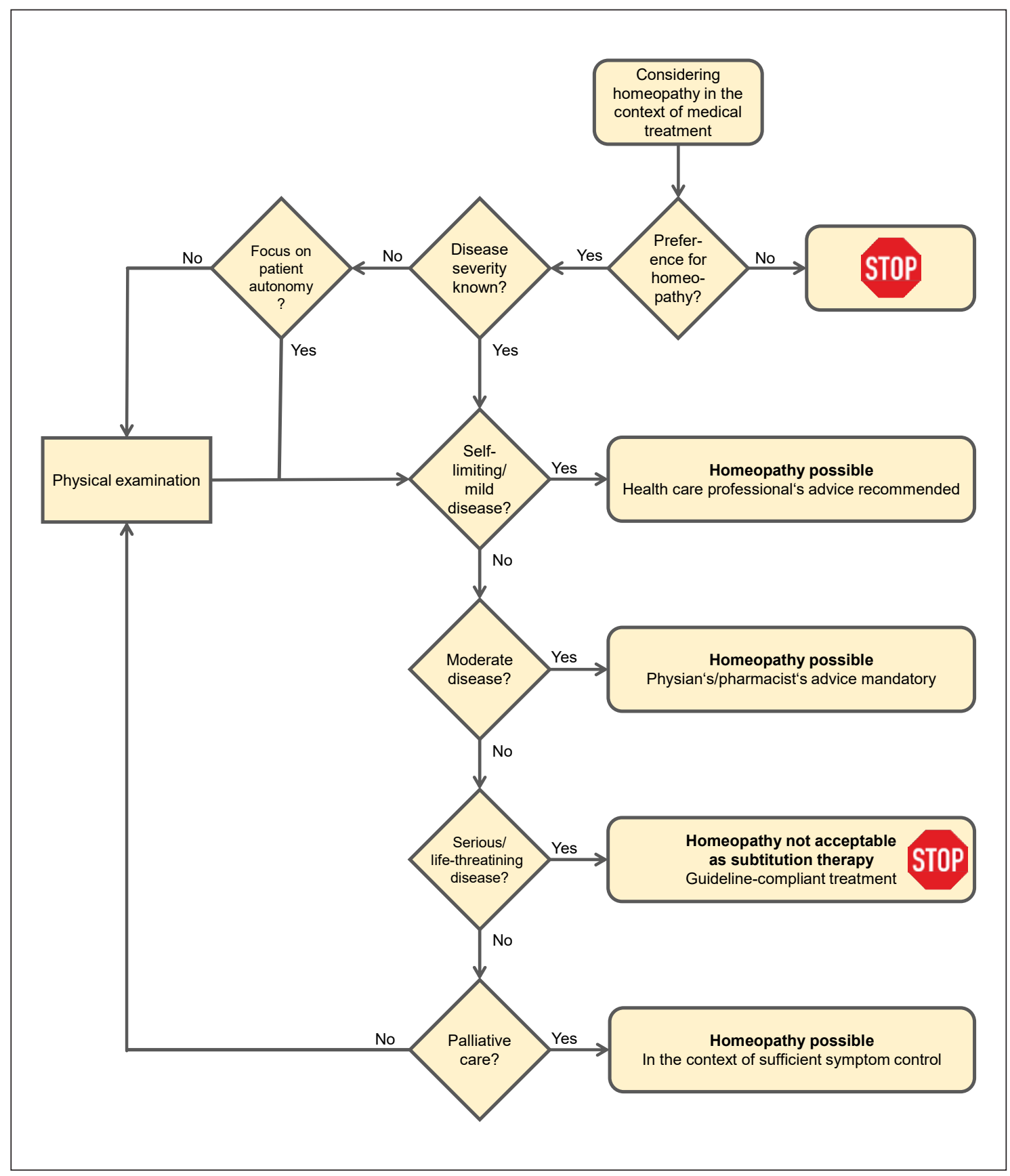

Fig. 1. To assist personal decisions for individuals who are open-minded towards homeopathy but feel riskaverse.

We realize a changing legal and regulatory environment that might jeopardize the further existence of homeopathy [110]. The conceptual constructs of homeopathy lack acceptance by mainstream science but do not justify tolerating double standards in toxicological risk assessment. Double standards in risk assessment always indicate room for improvement. Among European member states and even more in a worldwide comparison, regulations for homeopathic medicinal products vary considerably [111-113]. Harmonization of legal regulations for the toxicological assessment of possible human health hazards independently of the source and the intended use would help to minimize the use of different standards. The dose and not the mode of declaration for the active ingredient of a drug is responsible for the risk of adverse reactions.

\section{Lessons Learned from FSD Calculation}

In contrast to the points to consider [58], Buchholzer et al. [71] did not use the HMPWG decision tree but eval- 
uated the whole set of available toxicological data. They concluded that calculations assuming a usual daily dosage of approximately $1 \mathrm{~mL}$ or $1 \mathrm{~g}$ instead of $10 \mathrm{~mL}$ or $10 \mathrm{~g}$ [58] of the finished homeopathic medicinal products are based on sufficiently conservative assumptions. In a later publication, Buchholzer et al. did not calculate FSD but acceptable amounts per day which in some cases differed from the acceptable daily amounts determined by the HMPWG [1]. Obviously, different evaluation standards were used.

For practical purposes, it can be generalized that no material risk occurs in dilutions $\geq \mathrm{D} 9$, respectively $\geq \mathrm{D} 7$ or $\geq \mathrm{D} 8$ (depending on the manufacturing method), implying a TTC $\leq 0.15 \mu \mathrm{g} /$ person/day of the starting material. The HMPWG approach for homeopathic active substances uses $0.15 \mu \mathrm{g} /$ person/day, regardless of whether the substance shows genotoxic properties or not. In contrast, a TTC value of $1.5 \mu \mathrm{g} /$ person/day is set by the EMA for genotoxic herbal active substances [65] and for genotoxic impurities contained in medicinal products [66]. The HMPWG approach does not consider the complete TTC concept that includes the Cramer classes.

The use of double standards becomes obvious in the safety assessment of metals. The calculated acceptable daily amount for lifelong intake varies and depends on whether the same metal is present as a homeopathic active substance or as an impurity in a medicinal product.

From a toxicologist's point of view, the dose makes the toxicity and not the mode of declaration for the respective substance. Whenever comparisons of safety thresholds result in double standards, this realization implies room for improvement and harmonization.

\section{Implications for the Use of Homeopathy from a \\ Patient's Perspective}

The utilization of homeopathic medicinal products is popular and continuingly increasing, being a worldwide available form of complementary and alternative medicines and a medical system with a long-standing tradition of about 200 years [1].

In addition to the perspectives of the stakeholders discussed so far, we want to take a closer look at the individual perspective of a health care professional providing homeopathy or a patient using homeopathy in self-medication.

The controlled clinical data available for material risk assessment of homeopathic remedies support the qualitative statement that there is no material risk or, if a risk exists, it must be so small that is has not yet been established. On the other side, the clinical data do not allow any final risk quantification. If no indication of a robust risk factor from human data is known, human risk quantification stays speculative, and assessment of the effectiveness of preventive measures is impossible. Thus, a risk ladder would be of limited value to support personal decision making. To assist personal decisions for individuals who are open-minded towards homeopathy but feel riskaverse, we provide a thought experiment that is graphically depicted in Figure 1.

Our starting point are ethical recommendations on the implications of placebo and nocebo research for medical practice based on the current state of evidence [114]. Under this premise, homeopathy should be a way to improve patient health. However, homeopathic treatment does not come without risks, and the nonmaterial risk is defined by the actual health situation of the respective patient.

We illustrate this point by describing four scenarios: a person with meteorosensitivity; a patient with gastrointestinal complaints; a patient with a serious/life-threatening disease like potentially curable carcinoma or high blood pressure, and a moribund patient in palliative care (Fig. 1).

Safe medication practice is a multidisciplinary process involving the patients themselves, doctors, nurses, and pharmacists. From the perspective of education and training of all health professionals, pharmacists have the most knowledge about medicines, independently of whether prescribed by doctors or taken by patients on their own. Doctors in turn are most knowledgeable regarding diseases and diagnoses. Therefore, depending on the severity of disease states, patients should be advised either by health care professionals in general, pharmacists or doctors.

Meteorosensitivity is a self-limiting disease. For symptomatic treatment, homeopathy is a possibility. For this situation, the use of registered/authorized homeopathic remedies is without any material risk. In mild and selflimiting diseases, nonmaterial risks due to mind framing are not to be expected. Thus, for this situation, the use of registered/authorized homeopathic remedies is without any material risk, and even self-medication is an option.

The general limitations of self-medication also apply to homeopathic treatment: self-medication has its limits where the nature, frequency, or duration of symptoms recommends the consultation of a physician. In the EU, all authorized or registered medicinal products accessible to self-treatment provide warnings with their product information: they have a clear instruction to the patient in the package leaflet or on the label to consult a doctor, e.g. when symptoms persist.

In patients with gastrointestinal complaints, evidencebased management puts the focus on a range of diagnostic tests before initiating therapeutic intervention, which in many cases is pharmacological intervention [115]. However, in general medicine, diagnosis by exclusion of avoidable serious development, watchful waiting, and starting a probatory standard course of therapy are common [116]. 
Depending on the diagnosis, evidence-based guidelines can offer causal therapies or effective symptomatic interventions. Under these circumstances, there should be a stopping rule to substitute an effective evidence-based therapy option with a stand-alone homeopathic therapy. However, in real-world situations, self-medication including homeopathic remedies and recommendations by homeopaths is popular. What is the risk of an add-on option for common homeopathic products, e.g. nux vomica, arsenicum album, cocculus, or okoubaka? Homeopathic remedies with a marketing authorization or registration in Europe have no material risk. Mind framing on the health conditions of gastrointestinal complaints is very unlikely to be aggravated by the administration of a homeopathic remedy. Personally, we would neither recommend nor reject the personal decision to add a homeopathic product to the evidence-based management of gastrointestinal complaints.

In cases of serious, life-threatening conditions like potentially curable tumors or high blood pressure, evidencebased guideline-conform therapeutic management is mandatory. Such management implies a stopping rule for homeopathic medicine as a substitute for the necessary therapeutic intervention. If the patient is inclined to use homeopathy and the responsible health care professionals are open-minded towards complementary medicine, adding homeopathy to the conventional, guideline-coherent treatment is an option. It is self-evident that cancer treatment remains a case for integrative medicine led by qualified oncologists and includes a stopping rule for homeopathic medicine as substitution for guideline-conform therapeutic measures. Material and nonmaterial risks (i.e., neurobiological effects due to detailed patient education on possible side effects) can result from guideline-coherent interventions as well as from homeopathic remedies. The probabilities of risks of the necessary interventions always outweigh any theoretical unknown residual risk of a homeopathic intervention.
For moribund patients in palliative care, self-determination is essential. If a patient decides to substitute a supporting measure with homeopathic remedies or to add such remedies to the palliative regimen, this wish should be respected. Homeopathy poses no risk in this situation, given that adequate symptom control is provided in the overall palliative setting.

In conclusion, there is no material risk of homeopathic drugs with a market authorization or registration in a European country. A nonmaterial risk is conceivable, but such risks are in the range of common placebo/nocebo effects. Therefore, risks associated with homeopathic drugs are negligible compared to the everyday risks of daily living (e.g., traffic, household accidents, and lifestyle-associated risks) $[117,118]$.

\section{Acknowledgment}

We are grateful to Karolina Müller for preparing the reference list and to Monika Schöll for her linguistic editing of the manuscript.

\section{Disclosure Statement}

The authors have no conflicts of interest to declare.

\section{Funding Sources}

The manuscript was prepared without external funding.

\section{Author Contributions}

Both authors worked together from the initial draft to the final version of the paper and approved it.

\section{References}

1 Buchholzer ML, Kirch M, Kirchner C, Knoess W. Toxicological assessment compilation of selected examples of raw materials for homeopathic medicinal products. Regul Toxicol Pharmacol. 2019 Apr;103:253-73.

2 Davis A. Paracelsus: a quincentennial assessment. J R Soc Med. 1993 Nov;86(11):653-6.

3 Csupor D, Boros K, Hohmann J. Low potency homeopathic remedies and allopathic herbal medicines: is there an overlap? PLoS One. 2013 Sep;8(9):e74181.

4 Webster RK, Weinman J, Rubin GJ. A systematic review of factors that contribute to nocebo effects. Health Psychol. 2016 Dec;35(12): 1334-55.

5 Häuser W, Hansen E, Enck P. Nocebo phenomena in medicine: their relevance in everyday clinical practice. Dtsch Arztebl Int. 2012 Jun;109(26):459-65.
6 Petrie KJ, Rief W. Psychobiological Mechanisms of Placebo and Nocebo Effects: Pathways to Improve Treatments and Reduce Side Effects. Annu Rev Psychol. 2019 Jan;70(1):599-625.

7 Hall KT, Loscalzo J, Kaptchuk TJ. Genetics and the placebo effect: the placebome. Trends Mol Med. 2015 May;21(5):285-94

8 Zion SR, Crum AJ. Mindsets matter: a new framework for harnessing the placebo effect in modern medicine. Int Rev Neurobiol. 2018; 138:137-60.

9 Weihrauch TR, Gauler TC. Placebo-efficacy and adverse effects in controlled clinical trials. Arzneimittelforschung. 1999 May;49(5):385-93.

11 Lucassen P, Olesen F. Context as a drug: some consequences of placebo research for primary care. Scand J Prim Health Care. 2016 Dec; 34(4):428-33.
$12 \mathrm{Xu}$ JJ, Urban L. Predictive toxicology in drug safety. Cambridge: Cambridge University Press; 2010. https://doi.org/10.1017/ CBO9780511779053.

13 Mathie RT, Ramparsad N, Legg LA, Clausen J, Moss S, Davidson JR, et al. Randomised, double-blind, placebo-controlled trials of non-individualised homeopathic treatment: systematic review and meta-analysis. Syst Rev. 2017 Mar;6(1):63.

14 Oberbaum M, Yaniv I, Ben-Gal Y, Stein J, Ben-Zvi N, Freedman LS, et al. A randomized, controlled clinical trial of the homeopathic medication TRAUMEEL $S$ in the treatment of chemotherapy-induced stomatitis in children undergoing stem cell transplantation. Cancer. 2001 Aug;92(3): 684-90. 
15 Cialdella P, Boissel JP, Belon P; Groupe de recherche ASTRHO. Spécialités homéopathiques en substitution de benzodiazépines: étude en double-insu vs. placebo. Therapie. 2001 Jul-Aug;56(4):397-402.

16 Vierfeldertafel-Analyse. 2019. Available from: http://jumbo.uni-muenster.de/fileadmin/jumbo/applets/vierf.html

17 Stub T, Musial F, Kristoffersen AA, Alræk T, Liu J. Adverse effects of homeopathy, what do we know? A systematic review and meta-analysis of randomized controlled trials. Complement Ther Med. 2016 Jun;26:146-63.

18 Witt A, Kaufmann U, Bitschnau M, Tempfer C, Ozbal A, Haytouglu E, et al. Monthly itraconazole versus classic homeopathy for the treatment of recurrent vulvovaginal candidiasis: a randomised trial. BJOG. 2009 Oct; 116(11):1499-505.

19 Stam C, Bonnet MS, van Haselen RA. The efficacy and safety of a homeopathic gel in the treatment of acute low back pain: a multi-centre, randomised, double-blind comparative clinical trial. Br Homeopath J. 2001 Jan;90(1): 21-8.

20 van Haselen RA, Fisher PA. A randomized controlled trial comparing topical piroxicam gel with a homeopathic gel in osteoarthritis of the knee. Rheumatology (Oxford). 2000 Jul; 39(7):714-9.

21 Weiser M, Strösser W, Klein P. Homeopathic vs conventional treatment of vertigo: a randomized double-blind controlled clinical study. Arch Otolaryngol Head Neck Surg. 1998 Aug;124(8):879-85.

22 Weiser M, Gegenheimer LH, Klein P. A randomized equivalence trial comparing the efficacy and safety of Luffa comp.-Heel nasal spray with cromolyn sodium spray in the treatment of seasonal allergic rhinitis. Forsch Komplementarmed. 1999 Jun;6(3):142-8

23 Thinesse-Mallwitz M, Maydannik V, Keller T, Klement P. A Homeopathic Combination Preparation in the Treatment of Feverish Upper Respiratory Tract Infections: An International Randomized Controlled Trial. Forsch Komplementmed. 2015;22(3):163-70.

24 van Haselen R, Thinesse-Mallwitz M, Maidannyk V, Buskin SL, Weber S, Keller T, et al. The effectiveness and safety of a homeopathic medicinal product in pediatric upper respiratory tract infections with fever: a randomized controlled trial. Glob Pediatr Health. 2016; 3 2333794X16654851. https://doi.org/10.1177/ $2333794 X 16654851$.

25 Friese KH, Zabalotnyi DI. Homöopathie bei akuter Rhinosinusitis: eine doppelblinde, placebokontrollierte Studie belegt die Wirksamkeit und Verträglichkeit eines homöopathischen Kombinationsarzneimittels. HNO. 2007 Apr;55(4):271-7.

26 Beer AM, Fey S, Zimmer M, Teske W, Schremmer D, Wiebelitz KR. Wirksamkeit und Sicherheit eines homöopathischen Komplexpräparates bei chronischen Rückschmerzen. Doppelblinde, randomisierte, placebokontrollierte, klinische Studie. MMW Fortschr Med. 2012 Jun;154 Suppl 2:48-57.

27 Göbel H, Petersen-Braun M, Soyka D. Die Prävalenz von Kopfschmerzen in Deutschland: Eine Untersuchung an einer repräsentativen Stichprobe auf der Basis der Kopf- schmerzklassifikation der International Headache Society. Schmerz. 1993 Dec;7(4): 287-97.

28 Häuser W, Layer P, Henningsen P, Kruis W. Functional bowel disorders in adults. Dtsch Arztebl Int. 2012 Feb;109(5):83-94.

29 Pach D, Brinkhaus B, Roll S, Wegscheider K, Icke K, Willich SN, et al. Efficacy of injections with Disci/Rhus toxicodendron compositum for chronic low back pain-a randomized placebocontrolled trial. PLoS One. 2011;6(11):e26166.

30 Poruthukaren KJ, Palatty PL, Baliga MS, Suresh S. Clinical evaluation of Viscum album mother tincture as an antihypertensive: a pilot study. J Evid Based Complementary Altern Med. 2014 Jan;19(1):31-5.

31 Duijnhoven RG, Straus SM, Raine JM, de Boer A, Hoes AW, De Bruin ML. Number of patients studied prior to approval of new medicines: a database analysis. PLoS Med. 2013;10(3):e1001407.

32 Altman DG, Bland JM. Absence of evidence is not evidence of absence. BMJ. 1995 Aug; 311(7003): 485

33 Singh S, Gupta YK, Kalra P, Karwasra R, Kumar R, Nayak D, et al. Evaluation of safety profile of homoeopathic mother tinctures. Indian J Res Homoeopathy. 2014;8(2):81.

34 Books; 2019 [cited 2019 May 8]. Available from: https://www.oecd-ilibrary.org/books

35 Singh S, Kalra P, Karwasra R, Khurana A, Manchanda R, Gupta Y. Safety studies of homoeopathic drugs in acute, sub-acute and chronic toxicity in rats. Indian J Res Homoeopathy. 2017;11(1):48.

36 Turck D, Bresson J-L, Burlingame B, Dean T, Fairweather-Tait S, Heinonen M, et al. Guidance on the preparation and presentation of an application for authorisation of a novel food in the context of Regulation (EU) 2015/2283. EFS2 2016;14(11):54

37 Seyb HG. Botanik und Drogenkunde: I. und II. Teil. Wiesbaden: Vieweg \& Teubner; 1956. Die neue Fachbuchreihe für drogistische Ausbildung $3+4$

38 Ayyanar M, Subash-Babu P. Syzygium cumini (L.) Skeels: a review of its phytochemical constituents and traditional uses. Asian Pac J Trop Biomed. 2012 Mar;2(3):240-6.

39 Helmstädter A. Syzygium cumini (L.) SKEELS (Myrtaceae) against diabetes -125 years of research. Pharmazie. 2008 Feb;63(2):91-101.

40 Jagetia GC. A review on the role of jamun, Syzygium cumini skeels in the treatment of diabetes. IJCAM 2018;11(2). https://doi. org/10.15406/ijcam.2018.11.00374.

41 Bandiola TMB, Ignacio GB, Yunson EGA, Bandiola PDB. Syzygium cumini (L.) skeels: a review of its phytochemical constituents, toxicity studies and pharmacological uses. Int J Appl Pharm Biol Res. 2017;(2(6):15-23.

42 Prasad M, Venugopal SP, Alagarsamy V, Sridevi C. The preliminary phytochemical analysis and oral acute toxicity study of stem bark of Syzygium cumini. Int J Pharmacy Pharm Sci. 2015 Nov;8(1):209-13. Available from: https://innovareacademics.in/journals/ index.php/ijpps/article/view/9516

43 Silva SN, Abreu IC, Silva GF, Ribeiro RM, Lopes AS, Cartágenes MS, et al. The toxicity evaluation of Syzygium cumini leaves in rodents. Rev Bras Farmacogn. 2012;22(1):102-8.
44 Sekar M, Ayyanna C, Niranjan Kumar R. Siva Kumar A, Madhavi Lakshmi G, Siva Mallika Supraja N. Hepatotoxic effect of ethanolic extract of Syzygium cumini: linn leaves on experimental animals. Int $\mathrm{J}$ Res Pharmacol Pharmacother. 2015;4(3):288-94.

45 Krishnan HS. Glycowohl bei Diabetes: Fachinformation; 2018 [cited 2019 May 8]. Available from: https://www.apotheke-adhoc.de/fileadmin/user_upload/kompendium/Heilpflanzenwohl_Glycowohl/Glycowohl_Fachinformation_web.pdf

46 National Research Council. Intentional human dosing studies for EPA regulatory purposes: scientific and ethical issues. Washington: National Academies Press; 2004.

47 Ferdowsian HR, Beck N. Ethical and scientific considerations regarding animal testing and research. PLoS One. 2011;6(9):e24059.

48 Akhtar A. The flaws and human harms of animal experimentation. Camb Q Healthc Ethics. 2015 Oct;24(4):407-19.

49 About FD. Guidances; 2018 [cited 2019 May 8]. Available from: https://www.fda.gov/ drugs/guidance-compliance-regulatory-information/guidances-drugs

50 Nair AB, Jacob S. A simple practice guide for dose conversion between animals and human. J Basic Clin Pharm. 2016 Mar;7(2):27-31.

51 EFSA Panel on Contaminants in the Food Chain (CONTAM). Scientific Opinion on Pyrrolizidine alkaloids in food and feed. EFSA J. 2011;9(11):2406.

52 Martuzzi M, Tickner JA. The precautionary principle: protecting public health, the environment and the future of our children. Copenhagen: WHO Regional Office for Europe; 2004.

53 Kroes R, Kleiner J, Renwick A. The threshold of toxicological concern concept in risk assessment. Toxicol Sci. 2005 Aug;86(2):226-30.

54 Waddell WJ. Dose-response curves in chemical carcinogenesis. Nonlinearity Biol Toxicol Med. 2004 Jan;2(1):11-20.

55 Mattson MP. Hormesis defined. Ageing Res Rev. 2008 Jan;7(1):1-7.

56 Calabrese EJ. Hormesis is central to toxicology, pharmacology and risk assessment. Hum Exp Toxicol. 2010 Apr;29(4):249-61.

57 Homeopathic Medicinal Product Working Group. Consolidated list of first safe dilutions (FSD) list 1-4; 2018 [cited 2019 May 8]. Available from: http://www.hma.eu/fileadmin/dateien/Human_Medicines/01-About_HMA/ Working_Groups/HMPWG/2018_12_ H M P W G_Consolidated-Lis t FSD-1-4_20181217.pdf

58 Homeopathic Medicinal Product Working Group. Points to consider on non-clinical safety of homeopathic medicinal products of botanical, mineral and chemical origin; 2007 [cited 2019 May 8]. Available from: http:// www.hma.eu/fileadmin/dateien/Human_ Medicines/01-About_HMA/Working_ Groups/HMPWG/2007_07_biological_safety_bmco.pdf

59 Homeopathic Medicinal Product Working Group. Preamble to the 1st list of first safe dilutions (FSD); 2016 [cited 2019 May 8]. Available from: http://www.hma.eu/fileadmin/dateien/Human_Medicines/01-About_HMA/ Working_Groups/HMPWG/2016_11_Preamble_First_List_of_FSD.pdf 
60 Chitin; poly-N-acetyl-D-glucosamine (128991) fact sheet [cited 2019 May 8]. Available from: https://www3.epa.gov/pesticides/chem search/reg_actions/registration/fs_PC128991_1-Mar-01.pdf

61 Scientific opinion on the re-evaluation of gold (E 175) as a food additive. EFS2 2016;14(1): 4362.

62 Lakshmi C. Food coloring: the natural way 2014 [cited 2019 May 8]. Available from: http://www.isca.in/rjcs/Archives/v4/i2/15. ISCA-RJCS-2014-007.pdf

63 Munro IC, Ford RA, Kennepohl E, Sprenger JG. Correlation of structural class with no-observed-effect levels: a proposal for establishing a threshold of concern. Food Chem Toxicol. 1996 Sep;34(9):829-67.

64 Barlow SM, Kozianowski G, Würtzen G, Schlatter J. Threshold of toxicological concern for chemical substances present in the diet. Report of a workshop, 5-6 October 1999, Paris, France. Food Chem Toxicol. 2001 Sep; 39(9):893-905.

65 Committee on Herbal Medicinal Products (HMPC). Guideline on the assessment of genotoxicity of herbal substances/preparations; 2008 [cited 2019 Sep 12]. Available from: https://www.ema.europa.eu/en/documents/scientific-guideline/guideline-assessment-genotoxicity-herbal-substances/preparations_en.pdf

66 Committee for Medicinal Products for $\mathrm{Hu}$ man Use (CHMP), Committee for Medicinal Products for Veterinary Use (CVMP). Guideline on setting health based exposure limits for use in risk identification in the manufacture of different medicinal products in shared facilities; 2014 [cited 2019 Sep 12]. Available from: https://www.ema.europa.eu/en/documents/scientific-guideline/guideline-settinghealth-based-exposure-limits-use-risk-identification-manufacture-different_en.pdf

67 Cramer GM, Ford RA, Hall RL. Estimation of toxic hazard-a decision tree approach. Food Cosmet Toxicol. 1978 Jun;16(3):255-76.

68 Yang C, Barlow SM, Muldoon Jacobs KL, Vitcheva V, Boobis AR, Felter SP, et al. Thresholds of Toxicological Concern for cosmeticsrelated substances: new database, thresholds, and enrichment of chemical space. Food Chem Toxicol. 2017 Nov;109(Pt 1):170-93.

69 Patlewicz G, Jeliazkova N, Safford RJ, Worth AP, Aleksiev B. An evaluation of the implementation of the Cramer classification scheme in the Toxtree software. SAR QSAR Environ Res. 2008;19(5-6):495-524.

70 Jeliazkova N, Martinov M, Tcheremenskaia OJ, Networks M, Rydberg P, et al. Toxtree toxic hazard estimation by decision tree approach; 2019 [cited 2019 May 8]. Available from: http://toxtree.sourceforge.net/

71 Buchholzer ML, Werner C, Knoess W. Current concepts on integrative safety assessment of active substances of botanical, mineral or chemical origin in homeopathic medicinal products within the European regulatory framework. Regul Toxicol Pharmacol. 2014 Mar;68(2):193-200.

72 Hartung T. Thresholds of Toxicological Concern - Setting a threshold for testing below which there is little concern. ALTEX. 2017; 34(3):331-51.
73 More SJ, Bampidis V, Benford D, Bragard C, Halldorsson TI, Hernández-Jerez AF, et al. Guidance on the use of the threshold of toxicological concern approach in food safety assessment. EFS2 2019;17(6):293.

74 European Medicines Agency. Questions and answers on the "Guideline on the limits of genotoxic impurities"; 2010 [cited 2019 Jun 25]. Available from: https://www.ema.europa.eu/en/documents/scientific-guideline/ questions-answers-guideline-limits-genotoxic-impurities_en.pdf

75 Threshold of toxicological concern (TTC)based approach for certain substances: science approach document; 2016 [cited 2019 May 8]. Available from: https://www.ec.gc.ca/ ese-ees/326E3E17-730A-4878-BC25D 07303 A 4 D C $13 /$ H C $\% 20$ T T C $\% 20$ SciAD\%20EN\%202017-03-23.pdf

76 Products II. Q3B(R2): ICH harmonised tripartite guideline; 2006 [cited 2019 May 8]. Available from: https://www.ich.org/fileadmin/Public_Web_Site/ICH_Products/ Guidelines/Quality/Q3B_R2/Step4/Q3B_ R2__Guideline.pdf

77 World Health Organization. Lead [cited 2019 May 8]. Available from: https://www.who.int/ ipcs/assessment/public_health/lead/en/

78 World Health Organization. JECFA [cited 2019 May 8]. Available from: http://apps. who.int/food-additives-contaminants-jecfadatabase/chemical.aspx? chemID $=3511$

79 DVGW. Wasser; 2019 [cited 2019 May 8]. Available from: https://www.dvgw.de/themen/wasser/

80 European Directorate for the Quality of Medicines; Council of Europe. Food contact materials [cited 2019 May 8]. Available from: https://www.edqm.eu/en/food-contact-materials

81 European Directorate for the Quality of Medicines; Council of Europe. Consumer health protection guides; 2019. Available from: https://www.edqm.eu/en/consumer-healthprotection-guides

82 Bundesministerium der Justiz und für Verbraucherschutz. Bundesamt für Justiz: Gesetz über den Verkehr mit Arzneimitteln (Arzneimittelgesetz -AMG); 1976 [cited 2019 May 8]. Available from: https://www.gesetze-iminternet.de/amg_1976/AMG.pdf

83 BGA. BfARM. Plumbum metallicum; 1990 [cited 2019 May 28]. Available from: https:// buecher.heilpflanzen-welt.de/BGA-Kommission-D-Monographien/plumbum-metallicum.htm

84 Scientific opinion on dietary reference values for water. EFS2 2010;8(3):424.

85 National Academies Press (US). Possible Long-Term Health Effects of Short-Term Exposure to Chemical Agents. Volume 1. Washington (DC): Anticholinesterases and Anticholinergics; 1982.

86 Nation Center for Complementary and Integrative Health. FDA confirms elevated levels of belladonna in certain homeopathic teething products; 2017 [cited 2019 May 8]. Available from: https://nccih.nih.gov/node/10858

87 Heads of Medicines Agencies. Homeopathic Medicinal Products Working Group (HMPWG) [cited 2019 May 8]. Available from: https://www.hma.eu/380.html
88 Chan TY. Worldwide Occurrence and Investigations of Contamination of Herbal Medicines by Tropane Alkaloids. Toxins (Basel). 2017 Sep;9(9):E284.

89 US Food and Drug Administration. Title 21 - food and drugs: chapter I - Food and Drug Administration; 2018. Available from: https://www.accessdata.fda.gov/scripts/ cdrh / c fdocs / c f c fr/ C F R e a r ch $\mathrm{cfm}$ ?fr $=310.533$

90 Belladonna monograph for professionals drugs.com; 2019 [cited 2019 May 8]. Available from: https://www.drugs.com/monograph/belladonna.html

91 CBellergal ${ }^{\circledR}$ spacetabs: prescribing information; 2014 [cited 2019 May 8]. Available from: http://www.paladin-labs.com/our_ products/Bellergal_en.pdf

92 Bellergal spacetabs [cited 2019 May 8]. Available from: https://www.rexall.ca/articles/view/751/Bellergal-Spacetabs

93 European Pharmacopoeia Commission. Belladonna for homoeopathic preparations. In: European Pharmacopoeia, ed. 9.2, p. 4492-4 [cited 2019 Jun 27]. Available from: https://www.edqm.eu/en/european-pharmacopoeia-ph-eur-9th-edition

94 Kommission D. Bundesanzeiger Nr. 190a: Atropa belladonna (Belladonna); 1985 [cited 2019 Sep 12]. Available from: https:// buecher.heilpflanzen-welt.de/BGA-Kommission-D-Monographien/atropa-belladonna-belladonna.htm

95 Lauber U, Schnaufer R, Gredziak M, Kiesswetter Y. Analysis of rye grains and rye meals for ergot alkaloids. Mycotoxin Res. 2005 Dec;21(4):258-62.

96 Scientific opinion on ergot alkaloids in food and feed. EFS2 2012;10(7):551.

97 Arzneibuch H (HAB 2017): Amtliche Ausgabe. 9th ed. Stuttgart: Deutscher Apotheker Verlag; 2017.

98 Boericke W. Secale cornutum: ergot (Claviceps purpurea): homoeopathic materia medica; 1999 [cited 2019 May 8]. Available from: http://www.homeoint.org/books/ boericmm/s/sec.htm

99 European Medicines Agency. ICH Q3D elemental impurities [cited 2019 Jun 25]. Available from: https://www.ema.europa. eu/en/ich-q3d-elemental-impurities

$100 \mathrm{ICH}$ guideline M7 on assessment and control of DNA reactive (mutagenic) impurities in pharmaceuticals to limit potential carcinogenic risk: step 4; 2015 [cited 2019 May 8]. Available from: https://www.ema.europa. eu/en/documents/scientific-guideline/ guideline-assessment-control-dna-reactivemutagenic-impurities-pharmaceuticalslimit-potential_en.pdf

101 Chakraborti D, Mukherjee SC, Saha KC, Chowdhury UK, Rahman MM, Sengupta MK. Arsenic toxicity from homeopathic treatment. J Toxicol Clin Toxicol. 2003;41(7):963-7.

102 Drug products labeled as homeopathic guidance for FDA staff and industry. Draft guidance; 2017. Available from: https://www.fda. gov/media/109780/download

103 Safety issues in the preparation of homeopathic medicines [cited 2019 May 8]. Available from: https://www.who.int/medicines/ areas/traditional/Homeopathy.pdf 
104 US Food and Drug Administration. FDA warns manufacturers of products labeled as homeopathic for putting consumers at risk with significant violations of manufacturing quality standards; 2019 [cited 2019 Jun 25]. Available from: https://www.fda.gov/newsevents/press-announcements/fda-warnsmanufacturers-products-labeled-homeopathic-putting-consumers-risk-significantviolations

105 Freckelton I. The medico-scientific marginalisation of homeopathy: international legal and regulatory developments. J Law Med. 2015 Sep;23(1):7-23.

106 Johnson SB, Park HS, Gross CP, Yu JB. Complementary Medicine, Refusal of Conventional Cancer Therapy, and Survival Among Patients With Curable Cancers. JAMA Oncol. 2018 Oct;4(10):137581.

107 Campbell JE, Gossell-Williams M, Lee MG. A Review of Pharmacovigilance. West Indian Med J. 2014 Dec;63(7):771-4.

108 Traditional herbal medicinal products and simplified registrations for homeopathic medicinal products: pharmacovigilance requirements and EudraVigilance access: note for clarification; 2017 [cited 2019 May 8]. Available from: ttps://www.ema.europa.eu/ documents/regulatory-procedural-guideline/traditional-herbal-medicinal-products-simplified-registrations-homeopathicmedicinal-products_en.pdf
109 The Aurum Project - children's health research with natural medicine and homeopathy; 2016 [cited 2019 May 8]. Available from: https://aurumproject.org.au/\#!directory/ map

110 European Coalition on Homeopathic and Anthroposophic Medicinal Products. Following the debate: homeopathy and anthroposophic medicine; 2019 [cited 2019 May 8]. Available from: https://www.echamp.eu/ news-and-events/news/following-the-debate-homeopathy-and-anthroposophicmedicine- 4

111 Weltgesundheitsorganisation. Safety issues in the preparation of homeophatic medicines. Geneva: World Health Organization; 2009.

112 Borneman JP, Field RI. Regulation of homeopathic drug products. Am J Health Syst Pharm. 2006 Jan;63(1):86-91.

113 Wiesener S, Falkenberg T, Hegyi G, Hök J, Roberti di Sarsina P, Fønnebø V. Legal status and regulation of complementary and alternative medicine in Europe. Forsch Komplement Med. 2012;19(s2 Suppl 2):29-36.
114 Evers AW, Colloca L, Blease C, Annoni M, Atlas LY, Benedetti F, et al. Implications of Placebo and Nocebo Effects for Clinical Practice: expert Consensus. Psychother Psychosom. 2018;87(4):204-10.

115 Lamont JT. Evidence-based management of gastrointestinal diseases. Gastroenterol Rep (Oxf). 2015 Feb;3(1):1-2.

116 Kinoshita Y, Ishimura N, Ishihara S. Advantages and Disadvantages of Long-term Proton Pump Inhibitor Use. J Neurogastroenterol Motil. 2018 Apr;24(2):182-96.

117 Habs M, Binder K, Krauss S, Müller K, Ernst B, Valentini L, et al. A Balanced Risk-Benefit Analysis to Determine Human Risks Associated with Pyrrolizidine Alkaloids (PA)-The Case of Tea and Herbal Infusions. Nutrients. 2017 Jul;9(7):E717.

118 Habs M, Binder K, Krauss S, Müller K, Ernst B, Valentini L, et al. A Balanced Risk-Benefit Analysis to Determine Human Risks Associated with Pyrrolizidine Alkaloids (PA)-The Case of Herbal Medicinal Products Containing St. John's Wort Extracts (SJW). Nutrients. 2018 Jun;10(7):E804. 